\title{
UNA SERIE ANUAL DEL COMERCIO EXTERIOR ESPAÑOL (1821-1913)*
}

\author{
LEANDRO PRADOS DE LA ESCOSURA
}

Universidad de Alcalá de Henares

El propósito de este ensayo es ofrecer por vez primera una serie anual de las exportaciones e importaciones españolas que abarque desde la emancipación de las colonias continentales de Hispanoamérica hasta la Primera Guerra Mundial. Las nuevas series permitirán conocer la evolución del sector, tanto su tendencia como sus fluctuaciones, así como establecer el saldo de la balanza comercial ${ }^{1}$.

Este ejercicio estadístico completa la tarea de reconstrucción del comercio exterior llevada a cabo por Antonio Tena para los años 1914-1935, dando como resultado la serie más completa de las que se disponen para el estudio del pasado de la economía española ${ }^{2}$. En consecuencia, habrá perdido vigencia el aserto de Valentín Andrés Alvarez: «nuestras estadísticas del comercio exterior están falseadísimas por el número y la magnitud de los errores cometidos al fijar los valores de las mercancías» ${ }^{3}$.

Tras las severas críticas de Andrés Alvarez, sólo en fechas recientes han tenido lugar intentos de cuantificar el grado de error de las estadísticas oficiales de comercio exterior ${ }^{4}$. Dos rasgos han caracterizado a éstas: su consideración exclusiva del período para el que existen balanzas del comercio anuales y su concentración en la crítica de los valores unitarios o «valoraciones» utilizados para calcular los valores corrientes del comercio exterior.

* Deseo agradecer la ayuda recibida de Francisco Comín, Pablo Martín Aceña, César Molinas, Antonio Tena y Gabriel Tortella durante la realización de este estudio, así como los comentarios de un lector-árbitro anónimo. La investigación ha sido posible gracias a la financiación del Instituto de Estudios Fiscales.

I Para conocer las tendencias a grandes rasgos, cfr. Prados de la Escosura (1982 a, 1982 b). La limitación de espacio exige que la explicación de los cálculos realizados sea muy concisa. Información más precisa acerca de éstos se encuentra a disposición del lector interesado. El análisis económico de las series resultantes se ofrece en Prados de la Escosura $(1986 a)$, cap. 4 .

${ }_{2}^{2}$ Cfr. Tena (1985). Si se aceptan los resultados para el período 1940-1958 por Chamorro et al. (1975), se conocería la evolución del comercio exterior en la España contemporánea.

${ }^{3}$ Andrés Alvarez (1943), reproducido en Velarde (1969), p. 536.

4 Cfr. Tortella, Martín Aceña, Sanz y Zapata (1978); Prados de la Escosura (1981). 
En el presente estudio he explorado un aspecto diferente de las estadísticas del comercio exterior: las cantidades exportadas e importadas y la interacción de sus errores de medición con los hallados para las "valoraciones», con el fin de calcular su error conjunto. El método seguido es la comparación del comercio entre España y una muestra de países según las estadísticas españolas y extranjeras. Los países que integran esta muestra han sido elegidos por estar dotados de estadísticas comerciales fidedignas, así como por poseer una entidad significativa en el comercio español. La investigación no se agota con la realización de este contraste, que hará posible una crítica sobre bases más sólidas de las estadísticas oficiales, sino que, además, ofrece una serie anual de las exportaciones y las importaciones a precios corrientes, tanto para la época "preestadística» como para los años 1850-1913.

Los resultados obtenidos permiten ratificar análisis previos de Gwinner, Andrés Alvarez, Tortella y Prados de la Escosura: en general, los valores oficiales de las importaciones se encuentran exagerados, en tanto los de las exportaciones se hallan infravalorados. Paralelamente, los resultados alcanzados permiten advertir que los sesgos alcistas en los productos de importación son superiores en el caso de las manufacturas que en los de las materias primas y alimentos. Esta conclusión tiende a apoyar la hipótesis de Andrés Alvarez acerca de las manipulaciones políticas de las «valoraciones» con objeto de favorecer a los intereses proteccionistas. Por otra parte, este hecho pone de relieve la magnitud en que las «valoraciones» de los artículos importados estaban exageradas, pues alcanzan a compensar la subestimación de las cantidades comerciadas que produce el contrabando. Para la etapa anterior a 1850 se pone de manifiesto la incapacidad de la Administración española para elaborar unas estadísticas dignas de confianza para el comercio exterior, porque tanto los valores de las exportaciones como los de las importaciones están subestimados, como resultado del fracaso de las aduanas para registrar el tráfico de mercancías que tenía lugar por las fronteras. Las nuevas series permiten, por último, llevar a cabo una estimación alternativa de la balanza de mercancías, que arroja un saldo menos desfavorable que el que se desprende de las cifras oficiales, si bien permanece en posición deficitaria durante la mayor parte del período estudiado.

Cinco secciones componen este ensayo. En la primera se considera la evidencia empírica disponible para el análisis de los intercambios exteriores. Las posibles causas de los errores de las estadísticas oficiales de comercio exterior, así como las soluciones a explorar, son consideradas en la sección segunda a la luz de la historiografía. En la tercera se exponen las fuentes y procedimientos utilizados. La presentación de los sesgos estimados para las estadísticas oficiales constituye la sección cuarta. Finalmente, se ofrece una serie anual del comercio exterior para un período de noventa y tres años. 
La periodicidad anual de las estadísticas de comercio exterior data de 1849. Sus orígenes, no obstante, se remontan a la década de 1790 , cuando tiene lugar un creciente interés por la cuantificación de los recursos materiales del país ${ }^{5}$. El logro más destacado de los intentos de establecer una estadística de los intercambios con el extranjero y las colonias fueron las balanzas de comercio de $1792^{\circ}$. El estado de guerra en que se debate España por espacio de tres décadas, entre finales del siglo xvirr y la definitiva emancipación del imperio continental americano, abre un paréntesis en los intentos cuantificadores del comercio exterior ${ }^{7}$. Las reformas arancelarias de 1820 y 1825 marcan la reanudación de los esfuerzos en pro de unas balanzas de comercio anuales. Si bien esta frecuencia no se alcanzó, seis de los diez años siguientes a la reforma de 1825 disponen de estadísticas de comercio exterior, aunque su grado de elaboración y fiabilidad fluctúa de manera apreciable ${ }^{8}$. Tras la guerra carlista, y promulgado el arancel de 1841 , los intentos de establecer una estadística adecuada de comercio exterior se intensificaron, y hasta el año 1849, en que coinciden la promulgación del nuevo arancel y el inicio de la publicación anual de las balanzas de comercio, se dispone de noticias acerca del valor agregado anual del comercio exterior, si se exceptúa $1847^{9}$.

Resulta posible, por consiguiente, trazar, a grandes rasgos, la evolución del sector exterior durante las seis décadas referidas ${ }^{10}$. El conocimiento de sus fluctuaciones, así como las dudas acerca de su fiabilidad, exigen recurrir a otras fuentes tales como las estadísticas de comercio exterior de aquellas naciones que, además de mantener vinculaciones económicas con España, dispusieron de sistemas fidedignos de recogida y cómputo de los flujos de su comercio internacional ${ }^{11}$.

Resulta evidente, pues, la necesidad de elaborar una serie anual y plausible de las exportaciones y las importaciones españolas entre 1821 y 1849. En apariencia, sin embargo, no resultaría tan urgente disponer de series al-

${ }^{5}$ Véanse las referencias al interés ilustrado por la cuantificación y a sus limitaciones prácticas en Anes (1973), Fontana (1967), Matilla (1964) y Stein (1973).

- Balanza del comercio de España con las potencias extranjeras en el año de 1792 (Madrid, 1803); Balanza del comercio de España con los dominios de S. M. en América y en la India en el año de 1792 (Madrid, 1805).

7 Gracias a Matilla (1964), se conoce un intento de elaborar otra balanza de comercio para el año 1795, y que sólo llegó a realizarse para el comercio extranjero.

- Un comentario puede hallarse, junto a la presentación de sus principales resultados, en Prados de la Escosura (1982 a), p. 199 y apéndice B.

- Para el comercio en la década de 1840, véanse Prados de la Escosura (1982 a), apéndice B; $(1982 b)$, apéndice A, cuadro Ap-III.

${ }^{10}$ Cfr. Prados de la Escosura (1982 a, $\left.1984 a\right)$.

"Cfr. Prados de la Escosura (1984 b). 
ternativas para el período 1849-1913, en el que se cuenta con información oficial anual. Como se podrá advertir en la sección siguiente, los juicios que han merecido las estadísticas oficiales a contemporáneos y a historiadores y economistas conducen, sin embargo, a una visión diferente.

Dado el carácter disperso de la información disponible para el comercio exterior durante la primera mitad del siglo xIX, no resulta sorprendente que su imprecisión y su cobertura incompleta sea incluso advertida por los propios autores de las balanzas de comercio ${ }^{12}$. No obstante, las críticas contemporáneas afectan también a las estadísticas comerciales de la segunda mitad del siglo xIx y primer tercio del siglo $\mathrm{xx}$, cuando ya poseen periodicidad anual. La opinión del cónsul alemán en Madrid, Gwinner, a fines del pasado siglo, es que la evidencia de que se dispone para la balanza de servicios y la balanza de capital no apoya la idea de un considerable déficit crónico de la balanza de mercancías, como sugieren las estadísticas oficiales de comercio exterior ${ }^{13}$. Años más tarde, en la década de 1920, cuando los economistas contemporáneos tratan de estudiar los efectos de la Primera Guerra Mundial sobre la balanza comercial, o cuando, posteriormente, intentan analizar el impacto de la Gran Depresión sobre la economía, advierten, como Vandellós, que

«no tan sólo no merecen confianza alguna los valores atribuidos a nuestro comercio exterior, tomados en cifras absolutas, sino que tampoco podemos fiarnos de su movimiento relativo para descubrir la tendencia» ${ }^{14}$.

Una certera crítica de los defectos de las estadísticas comerciales desde mediados del siglo xIX a 1930 fue llevada a cabo por Valentín Andrés Alvarez tras la guerra civil ${ }^{15}$. En ella, además de enunciar los errores comunes a series de comercio exterior elaboradas a partir de una estimación oficial de los

${ }^{12}$ Véanse las introducciones a las balanzas de comercio de 1827 y 1843 . En la de este último año se realiza una comparación del comercio hispano-francés de acuerdo con las estadísticas de ambos países en 1842 y 1843, a fin de poner de relieve la inexactitud de las fuentes españolas.

${ }_{13}$ Gwinner (1973), pp. 288-289.

14 Vandellós (1931), p. 6. Un panorama completo de las opiniones que a los economistas de los años veinte y treinta merecían las series oficiales de comercio exterior puede consultarse en Tena (1985).

is Andrés Alvarez (1943, 1945). Las ideas de Andrés Alvarez son debatidas en Tortella et al. (1978) y Tena (1985). 
valores unitarios para las mercancías comerciadas, se sugerían atractivas hipótesis acerca de la dirección de los sesgos sistemáticos existentes en las «valoraciones» oficiales ${ }^{16}$. Las importaciones tenderían a hallarse exageradas, en tanto las exportaciones se encontrarían infravaloradas, con el resultado de ofrecer una balanza comercial más desfavorable de lo que era en realidad. Razones de indole política: las presiones de los intereses proteccionistas subyacían, en opinión de Andrés Alvarez, tras esta situación ${ }^{17}$. La conclusión extraída por Valentín Andrés Alvarez era tajante:

«si las valoraciones de nuestro comercio exterior, antes de 1930, no merecen confianza, la serie histórica de nuestras balanzas de comercio hasta la citada fecha nos es totalmente desconocida» ${ }^{18}$.

No obstante el patetismo que expresa la cita, Andrés Alvarez ofrecía una solución al problema: dado el grado de concentración del comercio exterior, bastaría valorar a precios de mercado — derivados de publicaciones periódicas españolas y extranjeras - a un reducido grupo de productos y comparar sus resultados con los valores oficiales correspondientes. El cociente de dividir los primeros entre los segundos permitiría rectificar los valores oficiales de las exportaciones e importaciones totales ${ }^{19}$. La segunda alternativa recogía una sugerencia de Gwinner, y consistía en confrontar el comercio entre España y sus principales proveedores y clientes según las estadísticas españolas $y$ extranjeras ${ }^{20}$.

El reto que plantea Andrés Alvarez: rectificar las series de comercio exterior a partir de la estimación del sesgo de las «valoraciones» oficiales de exportaciones e importaciones, fue aceptado por Tortella, Martín Aceña, Sanz y Zapata ${ }^{21}$. La muestra de productos considerados, al ser reducida -40 y 17 por 100 de los valores exportado e importado, respectivamente-, no permitió la rectificación de las cifras oficiales en el período 1875-1913, pero sí una primera estimación de su sesgo. Los resultados alcanzados en este trabajo proporcionan apoyo empírico a las opiniones de Gwinner y Andrés Alvarez, mostrando el sesgo a la baja, en el caso de las exportaciones, y al alza, en el

${ }^{16}$ Andrés Alvarez (1945), en Velarde (1969), p. 562.

17 Andrés Alvarez (1945), en Velarde (1969), pp. 551-556. Acerca de las influencias políticas en el establecimiento de las «valoraciones», serán de gran utilidad los resultados de la tesis de licenciatura de Leticia Alvarez Alonso (1985).

18 Andrés Alvarez (1945), en Velarde (1969), p. 550.

19 Ibidem, p. 562.

${ }^{20}$ Cfr. Gwinner (1973), p. 288.

${ }^{21}$ Tortella, Martín Aceña, Sanz y Zapata (1978) -en adelante figuran de manera abreviada como Tortella et al. (1978)- Un antecedente de este trabajo podría considerarse el estudio llevado a cabo por Vandellós (1931) para obtener una estimación alternativa a los valores oficiales del comercio exterior. Tena (1985), pp. 79.80, ha valorado críticamente esta contribución. 
de las importaciones, de las «valoraciones», así como la exageración de los saldos deficitarios de la balanza comercial, si bien las conclusiones extraídas por Tortella y sus colaboradores sugerían una mayor fiabilidad de las cifras oficiales que lo que suponían los estudios anteriores ${ }^{22}$.

Un segundo intento de medir la magnitud y el signo de los sesgos de las "valoraciones" oficiales de exportaciones e importaciones fue llevado a cabo por Prados de la Escosura, quien extendió el período hasta abarcar 1850-1913 y elevó la cobertura de la muestra $(44,4$ y 29,4 por 100 para la exportación y la importación, respectivamente) ${ }^{23}$. Esta, no obstante, permaneció siendo inadecuada para efectuar una rectificación de las series oficiales de comercio exterior ${ }^{24}$. Los resultados de este ejercicio corroboran las conclusiones de Tortella y sus colaboradores, si bien los sesgos estimados son menores ${ }^{25}$.

Es posible advertir que los intentos de cuantificación de los errores de las estadísticas de comercio exterior se han limitado, hasta el presente, a considerar la fiabilidad de los valores unitarios o «valoraciones» empleados para obtener las cifras oficiales de comercio exterior ${ }^{26}$. Esta actitud está fielmente expresada en el comentario de Tortella y colaboradores:

«no hay razón para suponer ningún sesgo sistemático en las "cifras reales" en lo que la terminología de nuestras estadísticas llama "cantidades": toneladas de carbón, hectolitros de vino, etc. Esto permite la utilización de las estadísticas para analizar la evolución en el comercio de mercancías individuales, pero no permite la agregación, porque ésta ha de hacerse en base a las valoraciones monetarias y aquí es donde nos encontramos el sesgo" ${ }^{27}$.

Esta postura no significa, en modo alguno, que Tortella y sus colaboradores no fuesen conscientes del problema del contrabando, sino que declinaron abordarlo en su trabajo ${ }^{28}$. Sin embargo, para las mercancías supuesta-

${ }^{22}$ Cfr. Tortella et al. (1978), pp. 508-511.

${ }^{23}$ Prados de la Escosura (1981), p. 52. Acerca de la representatividad de la muestra para las exportaciones en este trabajo en comparación con la de Tortella et al. (1978), véase aquél, p. 51.

24 Ibidem, p. 52.

25 Los resultados son reproducidos en el cuadro 2. Por su parte, los sesgos acumulados - que poseen el inconveniente de compensar aquellos de signo opuesto- son de - 12,8 y 11,0 por 100 para las exportaciones y las importaciones, respectivamente. Los sesgos acumulados que obtienen Tortella et al. (1978), p. 511, son de $-12,9$ y 20,1 por 100 para exportaciones e importaciones.

${ }_{26}$ Esta actitud se circunscribe al período anterior a 1914, pues en los años comprendidos entre 1914 y 1935 . Tena (1985) ha efectuado un estudio exhaustivo de las posibles fuentes de error de las estadísticas comerciales.

27 Tortella et al. (1978), p. 491.

28 Ibidem, pp. 494-495. 
mente no afectadas por el tráfico ilícito, estos investigadores aceptan explícitamente que las cantidades que figuran en las estadísticas oficiales se ajustan a las que eran comerciadas en la realidad ${ }^{29}$. La comparación entre las cantidades de algunas mercancías exportadas por España al resto del mundo, según las estadísticas oficiales españolas, y las importadas directamente de España por Gran Bretaña, de acuerdo a las estadísticas inglesas, muestra que éstas eran superiores a aquéllas ${ }^{30}$. Existen, pues, serias dudas acerca de la fiabilidad de las cantidades expresadas en las balanzas de comercio españolas. Así, las insuficiencias de las estadísticas trascienden el problema de las «valoraciones». Una cuestión adicional y que requiere un tratamiento específico es la del contrabando ${ }^{31}$.

La solución para el problema de los errores en las estadísticas oficiales de comercio exterior no puede venir dada únicamente por la corrección de los sesgos en las «valoraciones», sino que ha de combinar ésta con la rectificación de los sesgos en los volúmenes comerciados. A este propósito, la segunda alternativa propuesta por Andrés Alvarez resulta operativa ${ }^{32}$. Se trataría de estudiar los flujos comerciales entre España y aquellos países que, al tiempo que disponen de series largas y fiables para su comercio exterior, poseen un peso considerable en el comercio internacional español, y de contrastar las cifras que se deriven de las estadísticas nacionales y extranjeras, previamente realizados los ajustes correspondientes a los costes de transporte ${ }^{33}$.

El paso siguiente consiste, por tanto, en averiguar los errores de la muestra de países y comparar sus resultados con los obtenidos para la muestra de productos. Previamente se requiere, no obstante, considerar de manera sucinta las fuentes y procedimientos empleados.

\section{III}

La utilización de un contraste entre las estadísticas españolas y extranjeras para calcular el error de las balanzas de comercio de España posee las ventajas de tomar en consideración simultáneamente los sesgos de las «valoraciones» y los de las cantidades comerciadas, por una parte, y de no hallarse limitado en su aplicación por la existencia de series anuales para las estadísticas oficiales, por otra. Los países que integran la muestra son, con las va-

* Implícitamente, Prados de la Escosura (1981) adopta una posición similar.

30 Información procedente de Prados de la Escosura (1986 b).

${ }^{31}$ Para una estimación del contrabando de productos británicos por Portugal y Gibraltar, cfr. Prados de la Escosura (1984 b).

32 Andrés Alvarez (1945), p. 56.

${ }^{33}$ Tena (1985) ha puesto en práctica un sistema análogo. 
riaciones propias de un extenso período, Alemania, Bélgica, Francia, Gran Bretaña y Estados Unidos, que representan un mínimo de dos tercios del valor comerciado a lo largo del período que considera el estudio.

Las fases de adaptación y elaboración de las series procedentes de las estadísticas extranjeras al formato de las españolas se exponen a continuación:

a) Los valores del comercio exterior han de estar expresados a precios corrientes. Han sido precisos ajustes por medio de la aplicación de precios corrientes a las cantidades comerciadas, o bien de índices de precios a los valores oficiales a precios constantes. Varios han sido estos casos. En el caso del comercio hispano-británico, las cifras a precios corrientes las proporciona Prados de la Escosura ${ }^{34}$. Para el comercio español con los Estados Unidos se dispone de cifras oficiales hasta 1913, que resultan aceptables, aunque precisan de algunas correcciones de carácter menor ${ }^{35}$. Los valores oficiales del comercio hispano-francés, según las estadísticas galas, están calculados a precios corrientes, con la excepción del período 1827-1855, en que lo están a precios del año $1826^{36}$. La corrección de las importaciones de productos franceses se ha llevado a cabo a partir del indice de precios de importación para Francia elaborado por Lévy-Leboyer ${ }^{37}$. En el caso de las exportaciones, se ha utilizado el índice de precios de los productos españoles destinados a Gran Bretaña, procedente de Prados de la Escosura ${ }^{38}$. El motivo de esta elección radica en la similitud entre la composición de las exportaciones españolas a Francia y a Gran Bretaña ${ }^{39}$.

b) Las series han de corresponder a lo que, de acuerdo con la mayoría de las estadísticas de comercio exterior de Europa continental, se denomina "comercio especial», es decir, que tan sólo incluye a las importaciones netas $\longrightarrow$ destinadas al consumo interior - y a las exportaciones de mercancías de producción nacional. Es necesario, por consiguiente, eliminar las reexportaciones o comercio de tránsito. Esta situación tan sólo ocurre en los años 1821-1823, en los que aún subsiste el comercio de tránsito en escala signi-

34 Prados de la Escosura (1984 b).

${ }_{35}$ Véanse el apartado $d$ ) y las fuentes en el apéndice.

36 Para una discusión, cfr. Lévy-Leboyer (1977).

${ }^{37}$ Lévy-Leboyer (1970).

38 Prados de la Escosura (1985).

${ }^{39}$ Al estar valoradas las importaciones francesas de productos españoles a precios de 1826, ello equivale a un índice de volumen o cuántico del tipo Laspeyres. Si se le aplica un indice de precios del tipo Paasche, se obtienen valores a precios corrientes. Si $p_{i} q_{i} / p_{o} q_{o}$ representa al segundo y $p_{o} q_{i}$ al primero, siendo $p$ y $q$ precios y cantidades en cada año $i$ y en el año inicial $o$, de su producto resulta:

$$
\left(p_{i} q_{i} / p_{o} q_{i}\right) \times p_{o} q_{i}=p_{i} q_{i}
$$


ficativa. La corrección se ha realizado de acuerdo con el procedimiento expuesto por Prados de la Escosura ${ }^{39}$ bis.

c) El contrabando constituye un elemento de permanente distorsión de las cifras oficiales de comercio exterior en aquellos países que, como España durante el siglo xIx, estaban sometidos a una drástica legislación proteccionista. El tráfico ilícito afectaba casi exclusivamente a las mercancías importadas, pues los derechos arancelarios gravaban fuertemente a éstas, en especial a las manufacturas, en tanto eran moderados los que recaían sobre las exportaciones. Por otra parte, en las estadísticas extranjeras, al ser las importaciones españolas productos de exportación de estos países, los aranceles eran sensiblemente inferiores $y$, en consecuencia, no inducían al contrabando. De ahí que en las discrepancias entre las importaciones españolas, según las estadísticas españolas y extranjeras, se incorpore parte del tráfico ilícito. Existe, sin embargo, la posibilidad de llevar a cabo una estimación directa adicional de éste, y resulta de la existencia de estadísticas del tráfico entre algunos países y Gibraltar, así como de estimaciones contemporáneas y evidencia de carácter cualitativo acerca del contrabando que tenía lugar por la frontera de Portugal. Es posible, pues, llevar a cabo un cómputo aproximado del comercio ilegal. La base para esta estimación es necesariamente incompleta. Se trata de las estimaciones llevadas a cabo por Prados de la Escosura para las mercancías británicas introducidas a través de Gibraltar y Portugal, así como de estimaciones análogas realizadas a partir de las estadísticas norteamericanas que ofrecen el comercio entre los Estados Unidos y Gibraltar, donde se adopta un porcentaje idéntico al sugerido en el caso anterior para los artículos que, una vez en Gibraltar, seguían con destino al mercado español $(60 \text { por } 100)^{40}$.

d) Al utilizar estadísticas extranjeras, las exportaciones españolas son registradas como importaciones y suelen incluir en su valor total los costes de transporte, seguros y comisiones, pues, generalmente, son valoradas en el lugar de destino, es decir, c.i.f. Lo contrario sucede con las importaciones españolas - exportaciones desde el punto de vista de las estadísticas de los países considerados-, que se hallan valoradas en su lugar de origen, esto es, precios f.o.b. Será preciso, por consiguiente, eliminar fletes, seguros y comisiones mercantiles en el valor de las exportaciones españolas que ofrecen las estadísticas extranjeras y añadir los costes de transporte a las importaciones, de tal modo que las series que ofrecen las estadísticas extranjeras resulten homogéneas con las españolas, elaboradas éstas de acuerdo con la convención

39 bis Prados de la Escosura (1986a), cap. 2. En él se presenta una reconstrucción del comercio exterior español entre 1784 y 1820.

* Prados de la Escosura (1984 b). 
internacional de calcular f.o.b. las exportaciones y c.i.f. las importaciones ${ }^{4}$. La situación descrita afecta a las importaciones de todas las áreas geográficas que incluye la muestra, y a todas, con la excepción de los EE. UU., para las exportaciones. En los casos de Francia, Bélgica y Alemania he empleado la misma proporción que representaban anualmente fletes, seguros y comisiones mercantiles sobre el valor del comercio hispano-británico, para el que se posee información ${ }^{42}$. En el caso de los Estados Unidos he empleado el porcentaje que representan los fletes en el valor total de las exportaciones norteamericanas (factor-flete). Para el período 1820-60, North proporciona esta información ${ }^{43}$. En el período siguiente, hasta 1913, ha extendido al factor-flete de 1860 con la ayuda del índice de fletes construido por el propio North, como numerador, y, como denominador, el índice de precios de las exportaciones norteamericanas construido por Simon, para 1860-79, y Lipsey, para $1879.1913^{44}$. Las primas de seguros adoptadas las proporciona Simon a partir de 1860 y hasta 1900; para los años en los que no existe información ha sido realizada la suposición de que los seguros seguían una evolución similar, en dirección e intensidad, que los fletes ${ }^{45}$.

e) Se requiere, por último, la utilización de una unidad monetaria homogénea, bien sea la peseta-oro o la peseta corriente, siendo ésta la unidad en que vienen expresadas las estadísticas españolas ${ }^{* 6}$. La valuta española se mantuvo estable durante la mayor parte del período considerado, si bien experimentó una depreciación considerable en los años finales del siglo XIX y primeros del siglo actual ${ }^{47}$. Por su parte, las unidades monetarias en que figuran expresadas las cifras del comercio con España del grupo de países que integran la muestra, de acuerdo con las estadísticas extranjeras, no sufren oscilaciones apreciables respecto a la par ${ }^{48}$. Sólo en el caso de los Estados Unidos se opera una alteración sustancial cuando, entre 1862 y 1879 , se adopta un patrón fiduciario no convertible. Las series norteamericanas para estos años han sido convertidas en dólares-oro con ayuda de la prima del oro

"Cfr. League of Nations (1924).

42 Información procedente de Prados de la Escosura (1984 b).

${ }^{43}$ North (1960), pp. 607-608. Para una discusión del concepto factor-flete, cfr. North y Heston (1960).

"Simon (1960), p. 650; Lipsey (1962), pp. 142-143; North (1958), p. 549.

45 Simon (1960), p. 659 .

* Para una discusión, cfr. Prados de la Escosura (1981), pp. 48-50.

${ }^{47}$ Cfr. Tortella (1974), Sardá (1948).

* Así ocurre con la libra esterlina, el franco francés y el franco belga (desde 1860). El marco alemán se mantuvo estable entre 1882 y 1900 , con una leve depreciación en este último año. Las paridades legales -que se derivan de sus relaciones con el oroentre la peseta y las monedas mencionadas, además del dólar, son las siguientes: 1 franco francts $=1$ franco belga $=1$ peseta; 1 marco alemán=1,25 pesetas; 1 libra esterlina= $=25,12216$ pesetas; 1 dólar americano $=5,18262$ pesetas. Véase, a este respecto, Martínez Méndez (1983). 
en los EE. UU. que proporciona Simon ${ }^{49}$. Las series estimadas para las exportaciones y las importaciones se ofrecen, por tanto, en pesetas-oro y en pesetas corrientes. El tipo de cambio empleado para esta transformación procede de Tortella para los años 1870-90, de la Comisión del Patrón-oro en el período siguiente y, en los años comprendidos entre 1821 y 1870 , he construido una serie del tipo de cambio a partir de la información que recogen los London Price Current ${ }^{50}$.

\section{IV}

Una vez realizada la adaptación de las cifras que figuran en las estadísticas extranjeras al formato que presentan las españolas, para el comercio entre España y los países que componen la muestra, resulta posible efectuar una comparación de sus resultados respectivos que haga posible conocer los errores o sesgos sistemáticos de las cifras oficiales del comercio exterior español. Aunque el contraste llevado a cabo se centra en el período 1850-1913, para el que se dispone de series anuales de las balanzas de comercio, puede ofrecerse también una estimación de los errores en que incurren las estadísticas elaboradas por la Administración española en el segundo cuarto del siglo $\mathrm{xIX}$.

CUADRO 1

Errores o diferencias relativas de las estadísticas de comercio exterior, 1826-1849

(Porcentajes)

\begin{tabular}{|c|c|c|c|c|}
\hline & & $\bar{x}$ & $s$ & $C \nu$ \\
\hline A) & 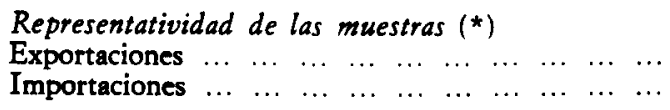 & $\begin{array}{l}61,1 \\
47,9\end{array}$ & $\begin{array}{l}2,1 \\
3,8\end{array}$ & $\begin{array}{l}3,4 \\
7,9\end{array}$ \\
\hline B) & 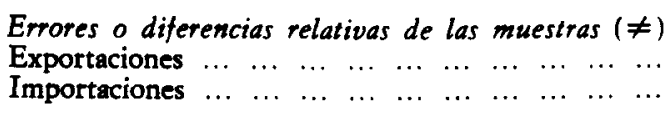 & $\begin{array}{l}-34,6 \\
-26,1\end{array}$ & $\begin{array}{r}11,9 \\
9,4\end{array}$ & $\begin{array}{l}34,4 \\
36,0\end{array}$ \\
\hline
\end{tabular}

(*) La muestra está compuesta por Estados Unidos, Francia y Gran Bretaña. Los años incluidos son $1826,1827,1829,1835,1842,1846$ y 1849.

$(\neq) \quad \bar{x}$ representa a la media aritmética, $s$ a la desviación típica y $c \nu$ al coeficiente de variación multiplicado por 100 . La fórmula utilizada para calcular el sesgo es: [ 100 (valor oficial - valor estimado) : valor estimado].

Fuentes: Véase el texto.

"Simon (1960), p. 63.

so Para el período 1870-1913, cfr. Tortella (1974); Tortella et al. (1978), p. 505. The Economist proporciona la cotización de la valuta española en Londres desde 1843. 
Puede advertirse la considerable infravaloración del comercio exterior español en la etapa más temprana de las estadísticas oficiales, resultado aparente de la incapacidad de la Administración para efectuar el registro de las mercancías que atravesaban las fronteras. Esta situación, que también afecta a los primeros años de la década de 1850 , muestra una tendencia declinante como consecuencia de las mejoras introducidas en el sistema aduanero.

En el cuadro 2 se presentan los resultados obtenidos para la segunda mitad del siglo xIx y principios del siglo xx. Es posible observar la cobertura superior de la muestra de países respecto a la de mercancías. Se advierte, además, que los coefícientes de variación resultan apreciablemente inferiores en aquel caso. En las exportaciones, por otra parte, destaca el carácter similar de la composición de las muestras de mercancías y de países, en la que dominan los productos alimentarios y las materias primas. La inclusión del vino común en la muestra de países es un elemento importante en la marcada diferencia del grado de cobertura a favor de ésta ${ }^{51}$. En las importaciones, por el contrario, las muestras de mercancías y países presentan una composición netamente diferenciada; mientras la primera está constituida por productos primarios casi exclusivamente, los artículos manufacturados son mayoritarios en la muestra de países, si se exceptúa a los Estados Unidos ${ }^{52}$. Es posible refinar ambas muestras hasta lograr que representen a los productos primarios y a los manufacturados de manera separada. Para ello he eliminado a los tejidos e hilados de algodón en la muestra de mercancías, en tanto en la muestra de países he excluido a los Estados Unidos y he descontado el valor del carbón de las importaciones procedentes de Gran Bretaña. Sin embargo, en este último caso, el resultado no llega a ser plenamente satisfactorio, pues, aun minoritario, subsiste un componente de productos primarios en la muestra de países.

El panel B del cuadro 2 ofrece los sesgos medios de las distintas muestras analizadas. Como habría de esperarse de una composición análoga, existe una elevada coincidencia entre los errores de ambas muestras para las exportaciones. Las diferencias relativas, por otra parte, se expresan en valores absolutos, a fin de evitar compensaciones entre sesgos de distinto signo. Las series anuales de las diferencias relativas recogidas en el cuadro AP-1, y que se muestran en el gráfico 1, permiten advertir que los valores oficiales de las exportaciones se hallan subestimados en la mayor parte del período considerado - de los sesenta y cuatro años, esto sucede para cuarenta y seis en la muestra de países y cincuenta y seis en la de mercancías-. A partir de la intro-

${ }^{31}$ Para conocer la entidad del vino común en las exportaciones españolas, cfr. Prados de la Escosura (1982 b), pp. 40-41.

${ }_{52}$ Incluso a finales del período considerado, al menos tres cuartas partes de las importaciones españolas de los EE. UU. estaban constituidas por productos primarios. 


\section{CUADRO 2}

\section{Errores o diferencias relativas de las estadísticas \\ de comercio exterior, 1850-1913}

(Porcentajes)

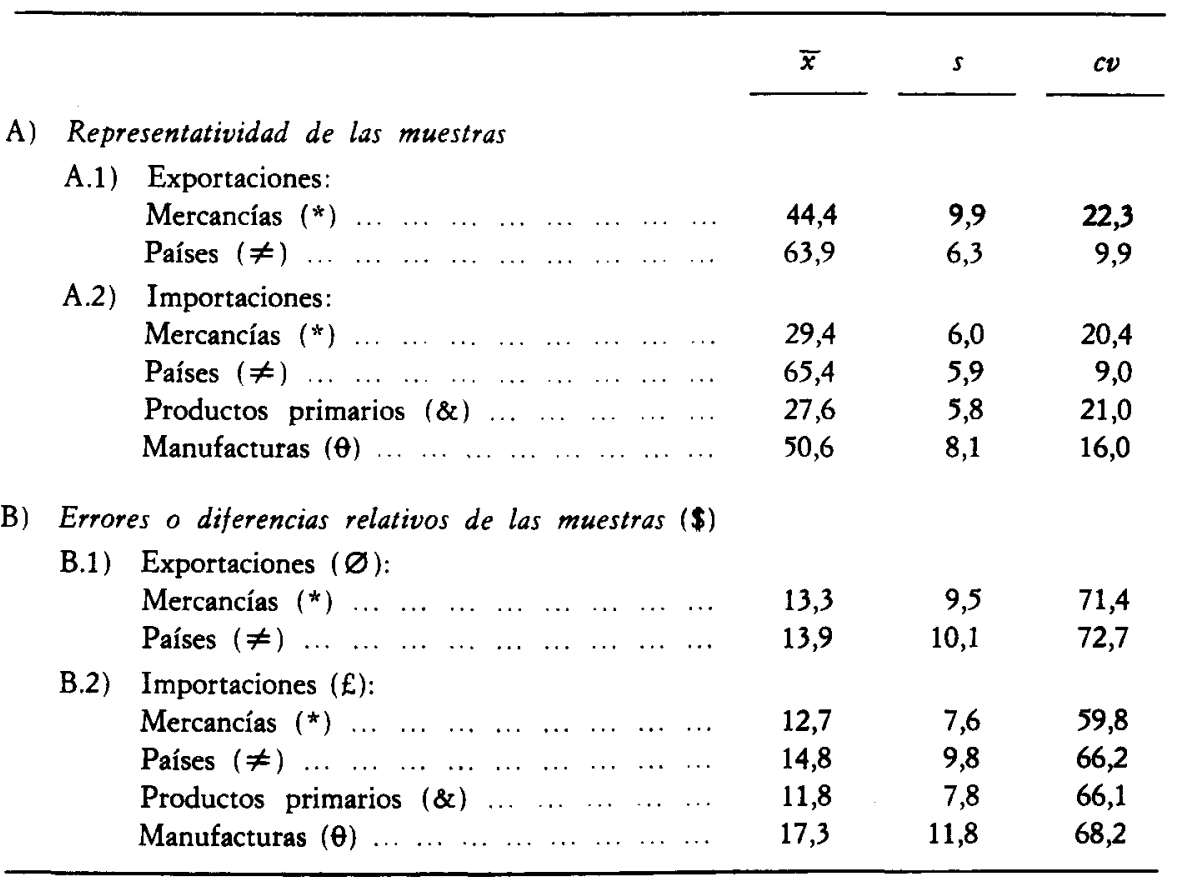

(*) Muestras de mercancías en Prados de la Escosura (1981), p. 52.

$(\neq)$ EE. UU., Francia, Gran Bretaña, Bélgica (desde 1860) y Alemania (desde 1882).

(\&) Muestra en (*) con la exclusión de tejidos e hilados de algodón.

$(\theta)$ Cfr. texto. Francia, Bélgica, Alemania y Gran Bretaña (excepto carbón).

(Ø) 100 (valor oficial - valor estimado)/valor estimado. En valor absoluto.

(£) 100 (valor oficial - valor estimado)/valor oficial. En valor absoluto.

(\$) El empleo de distinto denominador en $(\varnothing)$ y $(£)$ obedece a un intento de hacer comparables los sesgos de las exportaciones (a la baja) y de las importaciones (al alza). Cuando se utiliza como denominador el valor estimado, se reducen las subestimaciones y se aumentan las exageraciones. Lo contrario sucede si el denominador es el valor oficial.

Fuentes: Véanse el texto y apéndice, cuadros AP-1 y AP-2. 


\section{GRAFICO 1}

Exportaciones: errores o diferencias relativas de las muestras

$$
\left[100 \times\left(\frac{\mathrm{VO}-\mathrm{VE}}{\mathrm{VE}}\right)\right]
$$

Muestra de paises

...... Muestra de mercancias

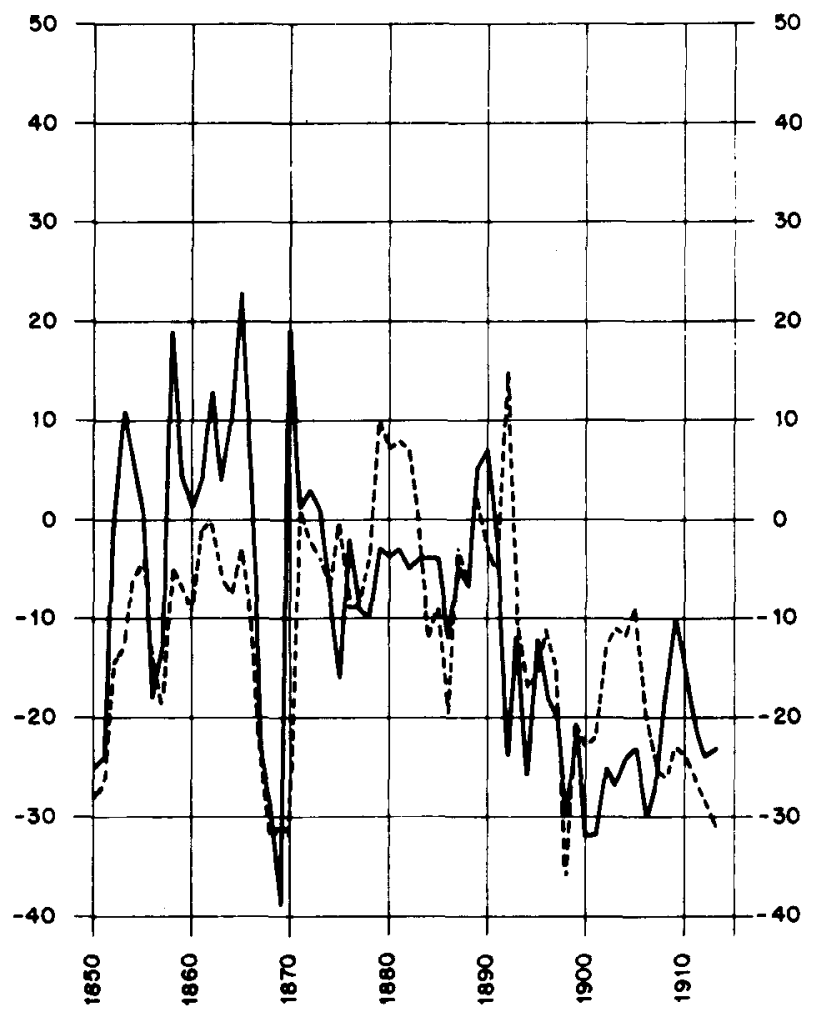

ducción de la legislación proteccionista de 1891, la infravaloración se hace mucho más acusada ${ }^{53}$.

${ }^{33}$ Obsérvense los sesgos de las muestras de mercancías y países antes y después de 1891 :

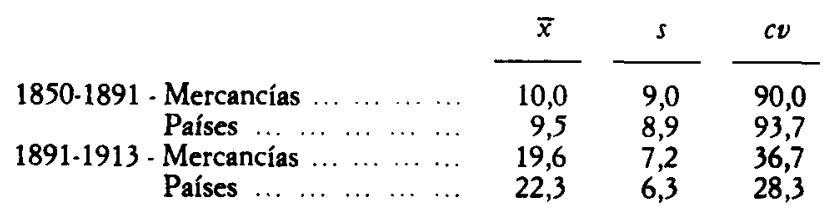




\section{GRAFICO 2}

Importaciones: errores o diferencias relativas de las muestras de mercancias $y$ países

$$
\left[100 \times\left(\frac{\mathrm{VO}-\mathrm{VE}}{\mathrm{VO}}\right)\right]
$$

Muestra de países

Muestra de mercancias

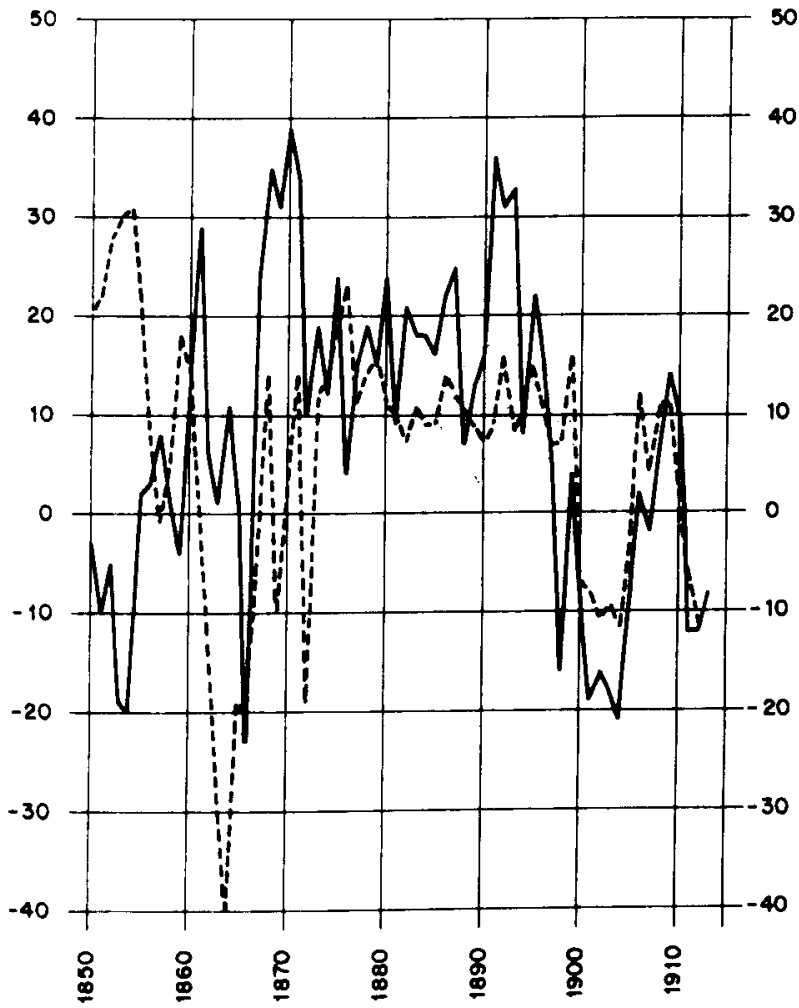

En el caso de las importaciones, el grado de coincidencia entre los sesgos de una y otra muestras es claramente inferior al que se ha apreciado para las exportaciones. La razón subyace en la distinta composición de éstas, como resulta patente cuando se contrastan los sesgos para los productos primarios y las manufacturas, que permite observar cómo la diferencia relativa media para estas últimas es superior en casi un 50 por 100 a la de aquéllos. La ma- 


\section{GRAFICO 3}

Importaciones: errores o diferencias relativas de las muestras de productos primarios y manufacturas

$$
\left[100 \times\left(\frac{\mathrm{VO}-\mathrm{VE}}{\mathrm{VO}}\right)\right]
$$

Muestra de productos manufacturados

Muestra de productos primarios

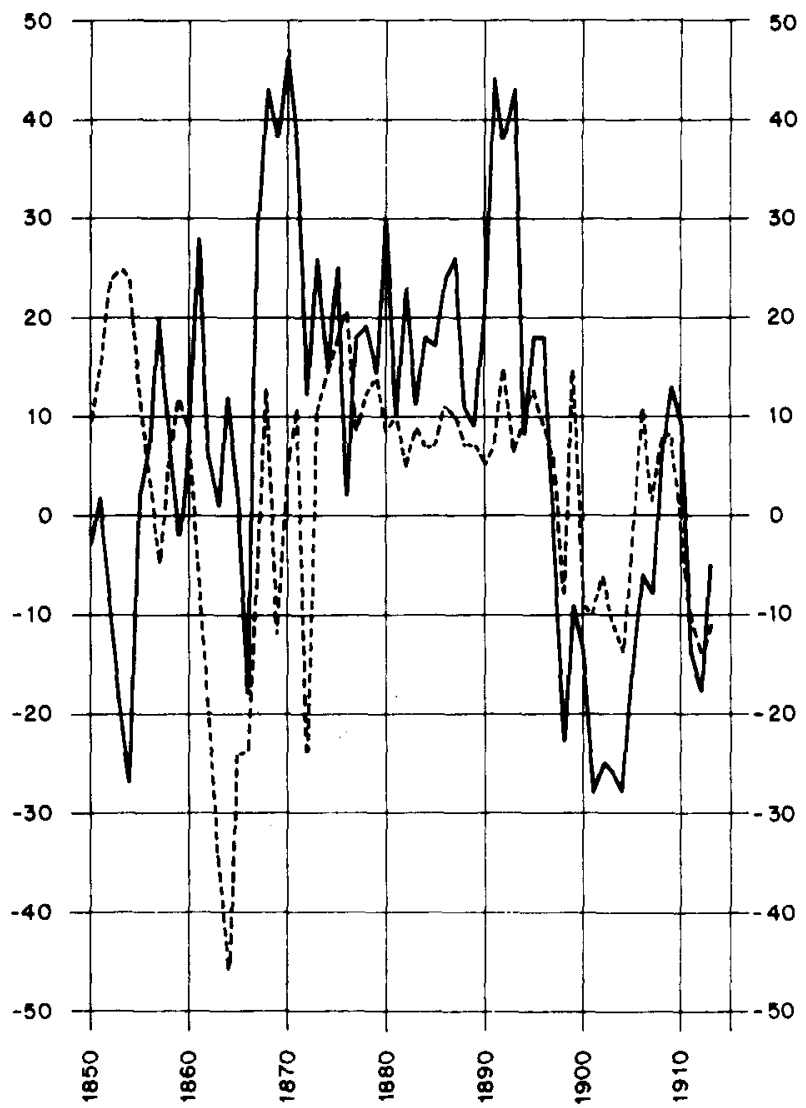


yor entidad de los sesgos sistemáticos al alza en el caso de los productos manufacturados apoya la hipótesis de Valentín Andrés Alvarez acerca de la manipulación de las "valoraciones» con objeto de servir a los intereses proteccionistas ${ }^{54}$. Por otto lado, es preciso señalar que, dado el carácter de la muestra de manufacturas - que mide conjuntamente los errores en los valores unitarios y en las cantidades-, resulta de gran interés advertir que las ocultaciones en el volumen comerciado, derivadas de la deficiencia de los registros aduaneros y del contrabando, fueron compensadas más que proporcionalmente por la exageración de las «valoraciones». La información anual obtenida para las diferencias relativas de la muestra de manufacturas muestra que, en cuarenta y cuatro de los sesenta y cuatro años considerados, los valores oficiales se encuentran exagerados. Unicamente durante el subperiodo 1897-1913 tiene lugar un sesgo sistemático a la baja en los valores oficiales de las importaciones. Una hipótesis explicativa pudiera ser el resultado de la tendencia por parte de las autoridades aduaneras a revisar sólo de tarde en tarde las tablas de valoraciones con las que se obtenían los valores oficiales de las mercancías comerciadas ${ }^{55}$. Tal actitud resulta coherente durante un período deflacionario si lo que se pretende es exagerar el valor de las importaciones, pero posee los efectos contrarios en una fase expansiva. Una consideración de la tendencia de los precios internacionales, en declive hasta mediados de la década de $\mathbf{1 8 9 0}$ $y$ desde entonces en ascenso, apoya esta interpretación ${ }^{56}$. Las consecuencias de mantener invariables las "valoraciones" tendrá consecuencias análogas en el caso de las exportaciones, y permite añadir otro elemento explicativo a la notable subestimación observada para éstas durante los dos últimos decenios del período analizado.

En síntesis, los resultados alcanzados en esta sección permiten reforzar, a la vez que matizar, los juicios emitidos acerca de la fiabilidad de las estadísticas españolas de comercio exterior por Gwinner, Vandellós y Andrés Alvarez, al tiempo que corroboran las conclusiones alcanzadas en anteriores ejercicios estadísticos por Tortella y sus colaboradores y por Prados de la Escosu-

${ }^{4}$ También podría argüirse que el elevado sesgo al alza de las «valoraciones» empleadas para las manufacturas pudiera provenir de la utilización de precios nacionales en lugar de los del mercado internacional, pues, dada la desventaja comparativa de la industria española, aquéllos tenderían a ser superiores a éstos. Debo este comentario a Gabriel Tortella, quien, además, sugiere que la situación contraria tendría lugar para el caso de las exportaciones.

${ }_{55}$ No sólo estudiosos españoles, como Valentín Alvarez, se hacen eco del mantenimiento de las «valoraciones» sin ser revisadas durante largos períodos de tiempo, sino incluso la Sociedad de Naciones lo pone de manifiesto en uno de sus estudios. Cfr. League of Nations (1924).

${ }_{56}$ Para la economía mundial, pueden consultarse los índices internacionales de precios de productos primarios y manufacturados en Lewis (1978), pp. 280-281. Para el comercio exterior, pueden verse los precios de exportación e importación en Prados de la Escosura (1985). 
$\mathrm{ra}^{5}$. La visión historiográfica resulta acertada, si bien los márgenes de error advertidos - a excepción de los encontrados para los valores oficiales de las importaciones de manufacturas - se hallan en un rango frecuente en las estadísticas históricas. Los elevados coeficientes de variación estimados previenen de su aceptación tal como aparecen en las balanzas de comercio y exigen continuar el presente ejercicio estadístico hasta culminar con la rectificación de las series oficiales. La sección final del estudio está consagrada a este intento, así como al de reconstruir el comercio entre 1821 y 1849 a partir de la evidencia fragmentaria disponible.

En esta última sección se presentan los resultados de la rectificación de las cifras oficiales del comercio exterior entre 1850 y 1913, así como de la reconstrucción para el período 1821-1849. Las muestras discutidas en la sección anterior constituyen la base de la elaboración de la nueva serie anual del comercio internacional de España, que abarca desde el fin del imperio colonial a la Primera Guerra Mundial. Los procedimientos seguidos difieren para las exportaciones y las importaciones. En el caso de las primeras coincide la composición de las muestras, y es necesario elegir una de ellas para llevar a cabo la reconstrucción de los flujos comerciales. Si se atiende al grado de precisión de los precios de mercado o valores unitarios a emplear, la muestra de mercancías resulta, sin duda, la más adecuada. Si se prefiere un elevado grado de cobertura, sin embargo, la ventaja es para la muestra de países. En la elección desempeña un papel determinante la ausencia del vino común en la primera y su incorporación en la segunda - ténganse en cuenta las exportaciones de vino a Francia en la década de 1880 , cuando este país experimentó la epidemia de filoxera- ${ }^{58}$. En consecuencia, la corrección de las cifras oficiales ha sido llevada a cabo a partir de la muestra de países para los años 1850-1913, así como para la reconstrucción del período 1821-1849, para el que no existe alternativa alguna. Para obtener el valor total de las exportaciones, el procedimiento seguido consiste en dividir, para el conjunto de países integrantes de la muestra, su valor estimado agregado por el porcentaje que, en valor oficial, representan éstos en las exportaciones totales.

${ }^{37}$ Gwinner (1973), Vandellós (1931), Andrés Alvarez (1943, 1945), Tortella et al. (1978), Prados de la Escosura (1981).

so pude hallar series apropiadas para los precios del vino común, producto nada homogéneo, como ponen de manifiesto Sánchez-Albornoz $(1979,1981)$ y GEHR (1982). Ante el riesgo de reducir la calidad de los precios o valores unitarios de la muestra de mercancías, el vino común no fue incluido en ésta. Véase Prados de la Escosura (1981), p. 51 , nota 12 . 
Para el período en el que no existen series oficiales anuales, he llevado a cabo el supuesto de aceptar como representativos de todo el período aquellos años para los que se dispone de información. Así, aceptado el supuesto arbitrario de que las exportaciones a los EE. UU., Francia y Gran Bretaña -el 61,1 por 100 del valor total exportado, según el promedio de 1826, 1827, 1829, $1835,1842,1843,1846$ y 1849 - mantenían una proporción anual idéntica a lo largo del período $1821-1849^{59}$.

El procedimiento seguido en el caso de las importaciones resulta más complejo. Ha sido expuesto cómo, a partir de las muestras de mercancías y de países, se han aislado productos primarios y manufacturas para los años 1850-1913 y, por consiguiente, la rectificación de las cifras oficiales de este período habrá de tomar en consideración los sesgos estimados para cada grupo de productos. En los años 1821-1849, la única vía de reconstrucción es la de la muestra de países, dado que las balanzas oficiales de comercio poseen un carácter disperso. No obstante, se llevará a cabo una corrección del sesgo que las manufacturas, al tener un peso excesivo en la muestra, introducen en los resultados obtenidos.

Entre 1821 y 1849 se ha estimado una serie de importaciones a partir del promedio que representa la participación de Francia, Gran Bretaña y Estados Unidos en las importaciones totales para aquellos años en que se dispone de balanzas de comercio oficiales $(47,9$ por 100$)$. La muestra empleada se encuentra, sin embargo, sesgada hacia los productos manufacturados, pues mientras que de Francia y Gran Bretaña se adquieren artículos terminados o semielaborados, tan sólo se importan productos primarios con carácter mayoritario de los EE. UU. A fin de comprobar en qué medida discrepaban los sesgos de los productos incluidos en la muestra (véase cuadro 1) y aquellos productos primarios no incluidos en ella, he optado por llevar a cabo una estimación del error o diferencia relativa de estos últimos para aquellos años en que existe información de las "valoraciones» oficiales aplicadas. El resultado para este grupo de mercancías (ron, azúcar, café, canela, cáñamo, lino y pimienta; algodón y carbón son excluidos, pues los recoge la muestra de países) ofrece una diferencia relativa media de 13,4 por $100^{60}$. Se advierte la menor entidad de este sesgo, que posee una ligera tendencia a la exageración, frente a la subestimación que presenta la muestra de países (donde se tienen en cuenta no solamente precios, sino también cantidades). Es conveniente, por tanto, corregir la serie reconstruida únicamente a partir de la muestra de países, a fin de tener en cuenta los sesgos diferentes en sentido e intensidad de los productos primarios y los manufacturados. El procedimiento empleado ha consistido en calcular la ratio del valor estimado a partir de las muestras de

59 Véase el cuadro 1.

so 6,2, y $c v: 46,3$. 
mercancías y países, al valor estimado con la muestra de países, exclusivamente para los años dispersos en que existe información de la muestra de mercancías. Esta ratio ha sido aplicada posteriormente a los valores anuales de las importaciones obtenidos a partir de la muestra de países.

La rectificación de las cifras oficiales de importación durante el periodo 1850-1913 resulta ser más precisa, pues toma en consideración los sesgos de las muestras de productos primarios y de manufacturas en cada año. La corrección de las series oficiales ha consistido en aplicar coeficientes, derivados de dividir los valores estimados entre los valores oficiales para cada muestra, a las importaciones totales de artículos manufacturados, por un lado, y de materias primas y alimentos, por otro, y, posteriormente, agregar los resultados obtenidos. Para ello he llevado a cabo una distribución de las importaciones oficiales entre productos primarios y manufacturas a partir de una amplia muestra de mercancías ${ }^{61}$. Existe, no obstante, un motivo de reserva acerca de la fiabilidad de la división porcentual entre un tipo de productos y otro que procede no sólo del carácter incompleto de la muestra utilizada para su cálculo, sino, principalmente, de la ocultación que tiene lugar en las estadísticas oficiales de parte de los artículos manufacturados introducidos en España, y cuyo origen se encuentra en los elevados aranceles que recaen sobre ellos, cuando no la prohibición expresa ${ }^{62}$. Resulta difícil lograr establecer una serie alternativa de importación de manufacturas que recoja este tráfico ilícito. En el intento de alcanzar este objetivo he seguido los pasos que a continuación se detallan. En primer lugar, he obtenido bandas o límites máximo y mínimo entre los que pudiera hallarse el porcentaje constituido por las manufacturas en las importaciones totales. El mínimo vendría dado, naturalmente, por la proporción que representan éstas en la muestra de mercancías importadas oficialmente. El máximo correspondería a la diferencia entre 100 y el porcentaje que el valor agregado de los productos primarios incluidos en la citada muestra de mercancías importadas oficialmente representa sobre el valor total de las importaciones. A fin de estimar cuál era el porcentaje más probable de los artículos manufacturados en el conjunto de las importaciones, he realizado el supuesto de considerar que éstos equivaldrían, de manera aproximada, al valor agregado de las importaciones españolas de Gran Bretaña (excluido el carbón), Francia, Alemania (desde 1882 ) y Bélgica (desde 1860) ${ }^{63}$. Es evidente que en las importaciones proce-

61 La muestra posee una representatividad media del 66,6 por 100 , siendo la desviación típica $(s) 6,1$ y el coeficiente de variación $(c v) 9,2$ por 100 .

62 Véanse las síntesis de las medidas de política comercial que para este período realizan Vicens Vives (1959), pp. 641-645, y Tortella (1981), pp. 148-157, así como el estudio de Leticia Alvarez (1985).

${ }^{63} \mathrm{La}$ inclusión de Bélgica y Alemania a partir de estas fechas obedece a que es desde entonces cuando se dispone de información adecuada para las estadísticas extranjeras a uti- 
dentes de este grupo de países se incluirían materias primas y alimentos en alguna proporción, pero también lo es que España adquiriría artículos acabados de países como Estados Unidos, Italia, Holanda, Suecia. He aceptado el supuesto arbitrario de que los porcentajes que significaban unas y otras serían idénticos $\mathrm{y}$, en consecuencia, la exageración que implica considerar que todos los productos franceses, británicos (a excepción del carbón), belgas (a partir de 1860) y alemanes (después de 1882) importados en España eran manufacturados, se compensaría con la que se deriva de aceptar como productos primarios a la totalidad de los mercancías procedentes de Estados Unidos, Holanda, Italia, Escandinavia, etc. Con muy escasas excepciones, las importaciones del grupo de países que se han identificado como los proveedores exclusivos de las manufacturas que alcanzan el mercado español se mantienen dentro de los límites máximo y mínimo establecidos para los productos manufacturados.

El paso siguiente ha consistido en obtener los nuevos valores de las importaciones de productos primarios y manufacturados de manera independiente. A partir de la utilización de los coeficientes que se obtienen entre los valores estimados y los oficiales en cada una de las muestras, he reevaluado las importaciones oficiales de materias primas y alimentos, de una parte, y de manufacturas, de otra. La nueva serie, derivada de agregar las dos anteriores, se ha contrastado con la que puede calcularse alternativamente utilizando la distribución entre productos primarios y manufacturas que ofrecen las estadísticas oficiales españolas para los años 1901-1913. La diferencia media entre los resultados de una y otra, 0,9 por 100 (con una tendencia a ser superior la serie obtenida a partir de las proporciones estimadas por mí para manufacturas y productos primarios), constituye una garantía de fiabilidad de la nueva serie de importaciones ${ }^{64}$. A este test hay que añadir que la serie oficial de importación ha sido rectificada a partir de dos muestras que, en conjunto, poseen una representatividad media del 72,8 por 100 (esto es, el resultado de sumar los porcentajes representados por las muestras de productos primarios y de manufacturas en el cuadro 2).

La serie elaborada para las importaciones incorpora, como se ha expuesto anteriormente, comercio ilícito desde el punto de vista de las autoridades españolas. Sin embargo, sólo incorpora a éste parcialmente, pues existe contrabando a través de Gibraltar y Portugal que no ha sido incluido en la nueva serie. He llevado a cabo una estimación incompleta del contrabando a partir del comercio británico con Portugal y Gibraltar, así como el comercio nor-

lizar en la corrección de las españolas. Es preciso señalar, sin embargo, que durante el período cubierto es cuando estos países adquieren importancia en las importaciones españolas. Véase, a este respecto, Prados de la Escosura (1982 b), pp. 47-48.

64 Siendo $s: 0,5$, y $c v: 55,6$. 
teamericano con la colonia inglesa ${ }^{65}$. Esta estimación ha sido añadida a la nueva serie de importaciones (importaciones directas) a fin de obtener las importaciones totales. El estudio de la composición de las exportaciones británicas y norteamericanas a Gibraltar, así como británicas a Portugal, permite establecer que mientras las mercancías de procedencia inglesa que alcanzaban el mercado español por esta vía eran fundamentalmente manufacturas, las de origen norteamericano eran productos primarios.

Los resultados del ejercicio de reconstrucción realizado se ofrecen en los cuadros AP-3 a AP-7 y gráficos 4 a 7 , con expresión de los valores en pesetas-oro y pesetas corrientes de exportaciones e importaciones, así como la presentación de la serie de saldo estimado para la balanza de mercancías, que aparece en los gráficos 8 y 9.

Resulta de interés llevar a cabo una comparación entre las nuevas series de comercio exterior y las que ofrecen las estadísticas oficiales. Además de a precios corrientes, el ejercicio puede realizarse a precios constantes, pues se dispone de índices de precios recientemente construidos para este período ${ }^{*}$. El cuadro 3 sintetiza los resultados. Durante el siglo xIX, en su conjunto, la nueva serie de exportaciones crece, en comparación con la oficial, algo más lentamente a precios corrientes y de manera idéntica a precios constantes. Las importaciones, por su parte, muestran un crecimiento menor a precios corrientes y mayor a precios constantes. Del contraste entre las series estimadas y oficiales para las distintas fases de la política arancelaria se desprenden los resultados que a continuación se exponen.

Entre 1821 y 1849 , el crecimiento, tanto de las exportaciones como de las importaciones, es inferior al que se obtiene a partir de la evidencia fragmentaria que proporcionan las balanzas de comercio oficiales. Anteriormente ha sido puesta de relieve la incapacidad de la administración aduanera para compilar unas estadísticas fidedignas. Este hecho supone que, a medida que se retrocede en el tiempo, el grado de infravaloración del comercio exterior sea superior, y el resultado es la exageración del crecimiento de las series. Las consecuencias de la subestimación de las estadísticas oficiales son, por una parte, que los niveles de comercio exterior, tras la guerra de la Independencia y la emancipación de las colonias del continente americano, son superiores a los que indican las estadísticas oficiales de aduanas; por otra parte, las nue-

6s Véase sección III, apartado $c$ ), de este ensayo.

* Prados de la Escosura (1985). A pesar de ser las series de precios más precisas de que se dispone para el comercio exterior, conviene tener en cuenta que corresponden al comercio hispano-británico y que, en consecuencia, están determinadas por la composición del comercio con Gran Bretaña. Así, mientras que existe un grado de coincidencia considerable para las exportaciones, se echan a faltar algunos productos alimentarios clave, como el trigo, o materias primas, como el algodón en rama, en las importaciones. 


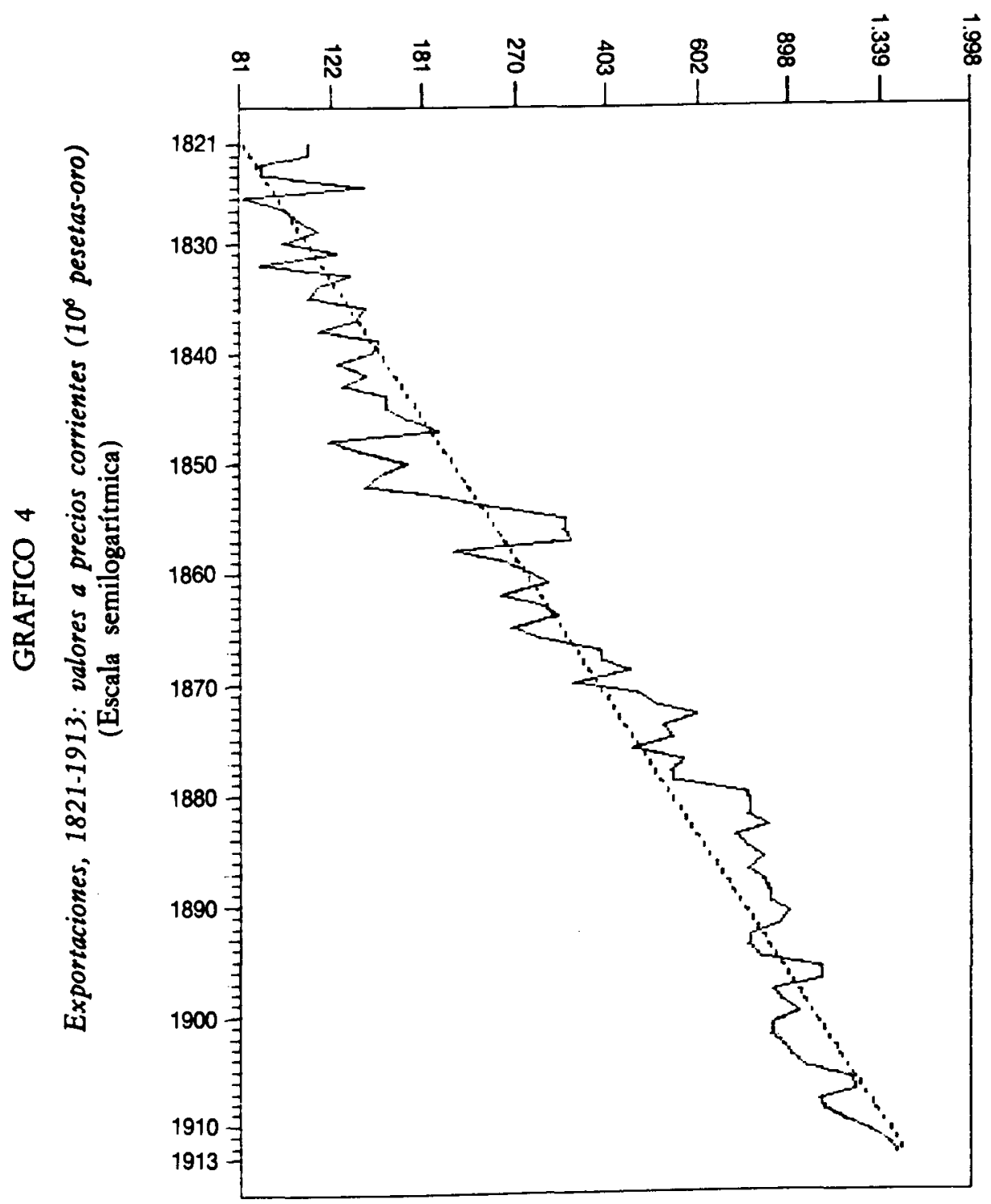




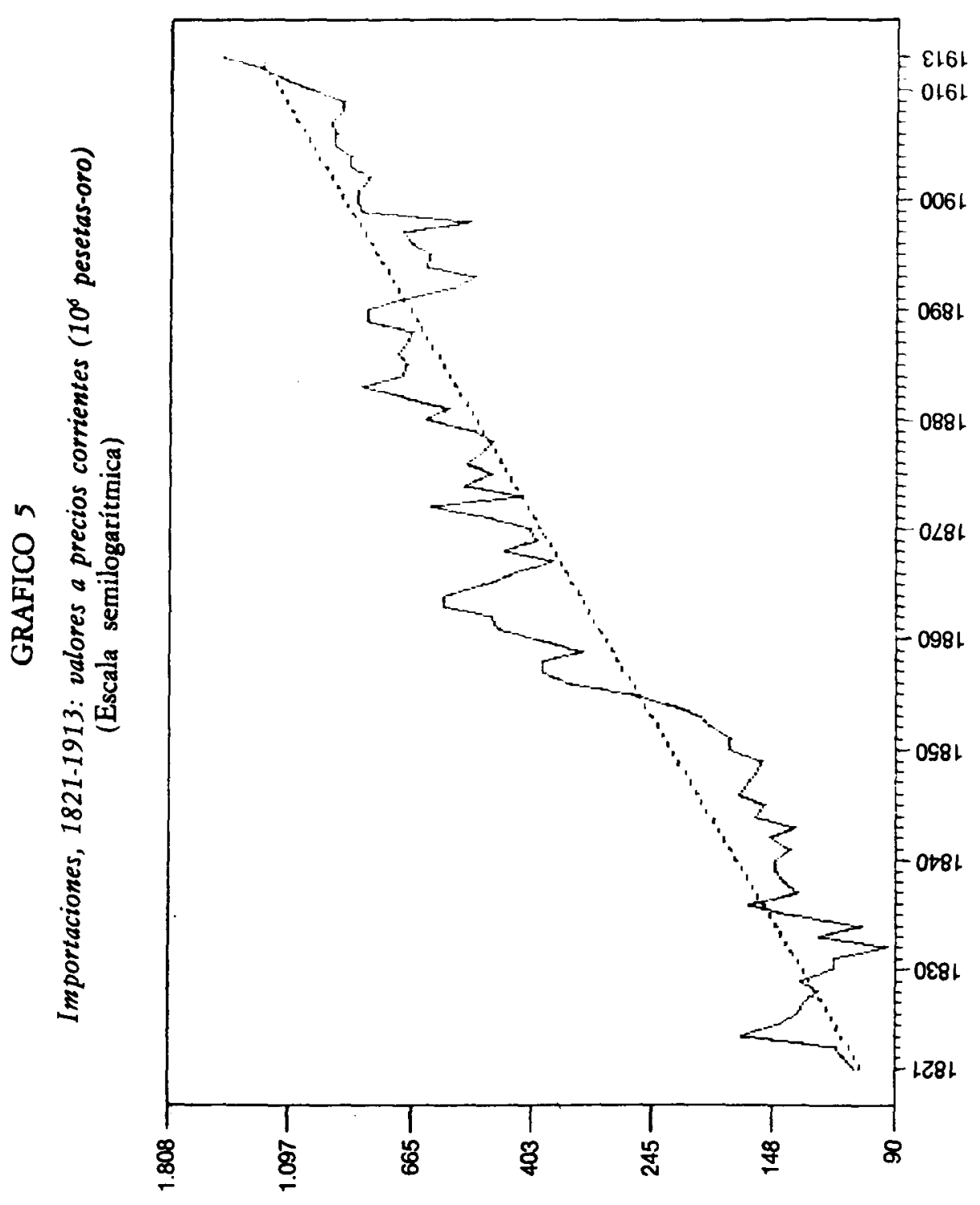




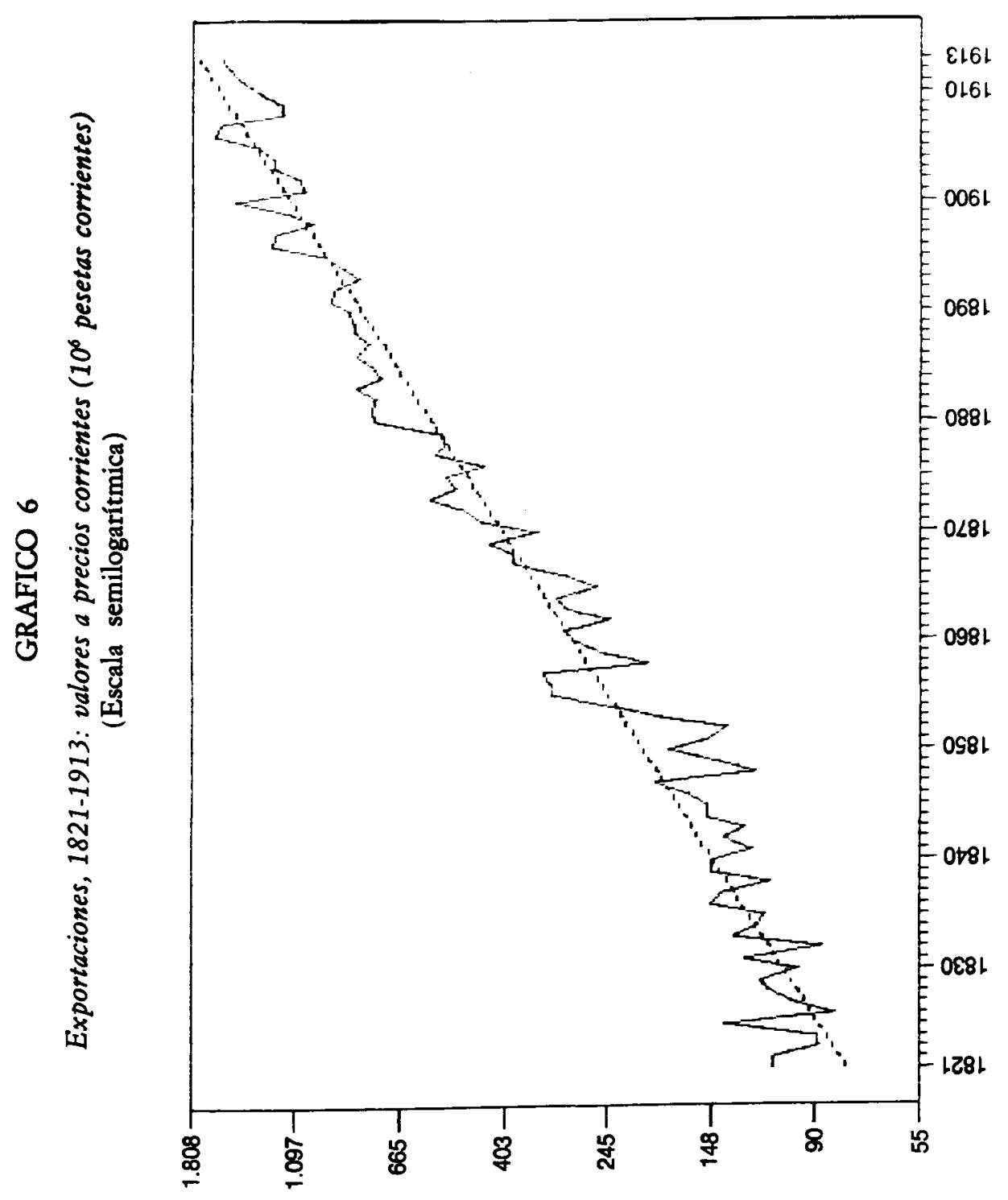




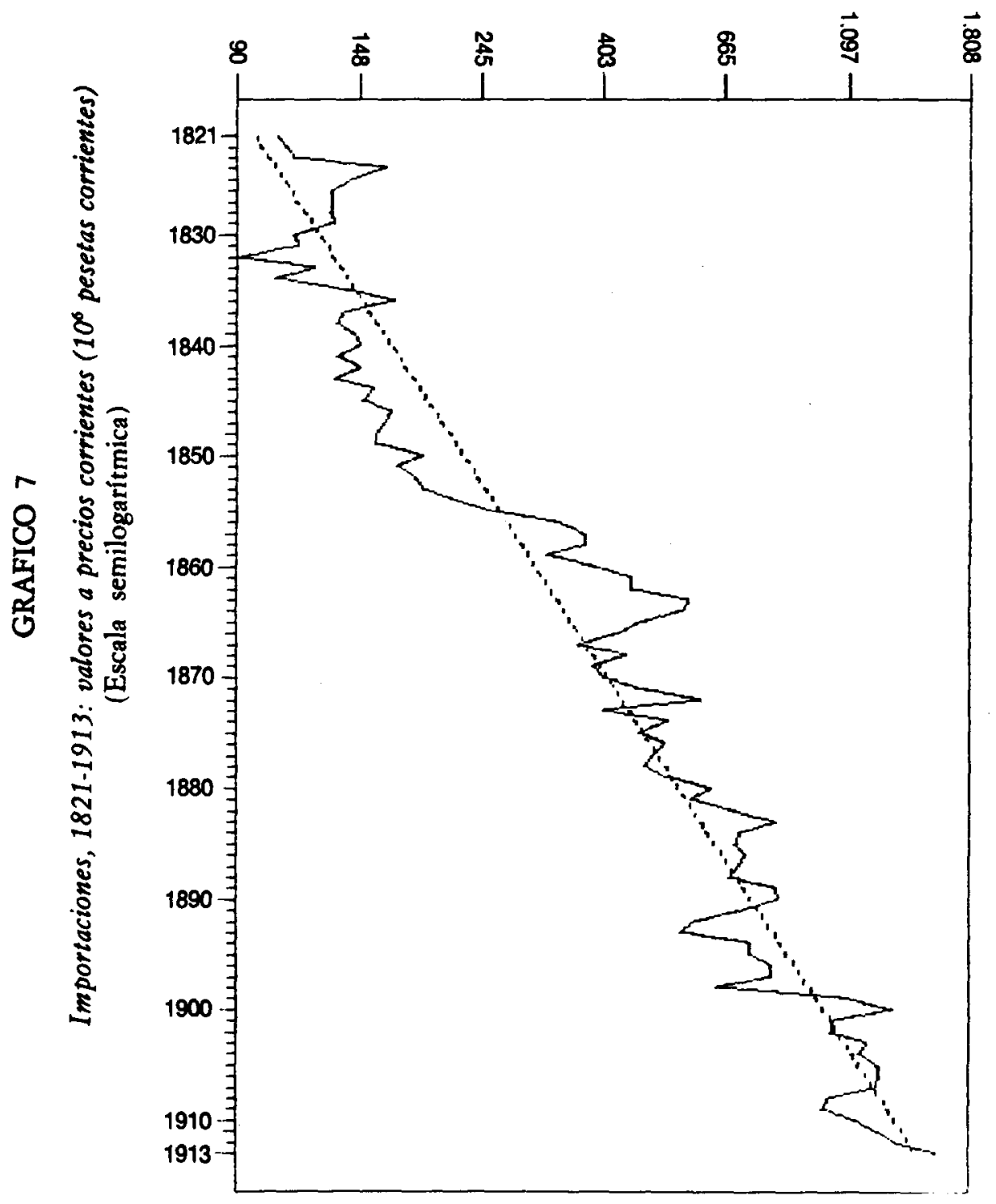




\section{CUADRO 3}

Tasas de crecimiento anual del comercio exterior, 1821-1913 (\%) (Ajuste exponencial)

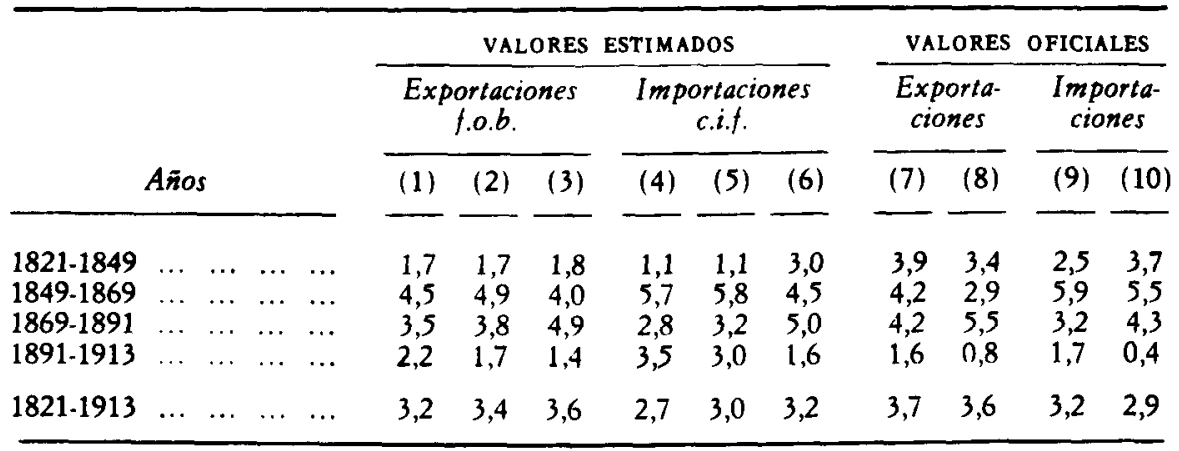

(1) Precios corrientes, pesetas-oro.

(2) Precios corrientes, pesetas corrientes.

(3) Precios constantes.

(4) Precios corrientes, pesetas-oro.

(5) Precios corrientes, pesetas corrientes.

(6) Precios constantes.

(7) Precios corrientes, pesetas corrientes.

(8) Precios constantes.

(9) Precios corrientes, pesetas corrientes.

(10) Precios constantes.

FuENTES: Valores estimados a precios corrientes, apéndice, cuadro AP-3; valores estimados a precios constantes, cuadro AP.3 y Prados de la Escosura (1985), cuadro A-2 (índices Fisher de precios de exportación e importación); valores oficiales, Prados de la Escosura (1982 b), cuadro, pp. 23-24, cuadros 1 y 2.

vas series muestran una recuperación del comercio más gradual de lo que hasta ahora se suponía ${ }^{67}$.

Los años comprendidos entre 1849 y 1891 son, como ya indicaban las estadísticas oficiales, de fuerte expansión. Sin embargo, las nuevas series presentan discrepancias con éstas. Así, las exportaciones estimadas crecieron más aprisa entre 1849 y 1869 , y menos entre 1869 y 1891 . Lo contrario sucede para las importaciones.

Por último, entre 1891 y 1913, las nuevas series de comercio exterior ofrecen una evolución más favorable que la apuntada por las estadísticas oficiales: tanto a precios corrientes como a precios constantes, la desaceleración de exportaciones e importaciones es inferior a la sugerida por éstas.

" Una reconsideración del comercio exterior durante las guerras napoleónicas y el pe. ríodo de posguerra se lleva a cabo en Prados de la Escosura (1986 a), caps. 2 y 4. 
La evolución de la balanza comercial es, quizá, el resultado más revisionista que proporcionan las nuevas series de exportaciones e importaciones. Una crónica posición deficitaria es la visión imperante en la historiografía. Tres fases pueden distinguirse en el comportamiento de la balanza de mercancías. Entre 1821 y 1850 , los saldos estimados muestran una tendencia a la estabilidad, con déficit moderados ${ }^{68}$. Es interesante señalar que, además de contradecir la interpretación tradicional, el saldo obtenido en estos años discrepa abiertamente del que sugieren Témime, Broder y Chastagneret ${ }^{69}$. A partir de un estudio inédito de Broder, estos autores consideran que el déficit acumulado asciende a 463 millones de pesos ( 2.315 millones de pesetas), es decir, un promedio anual de 77 millones de pesetas; mientras que de la nueva

\section{GRAFICO 8}

Saldo de la balanza de mercancias, 1821.1913 (106 pesetas-oro)

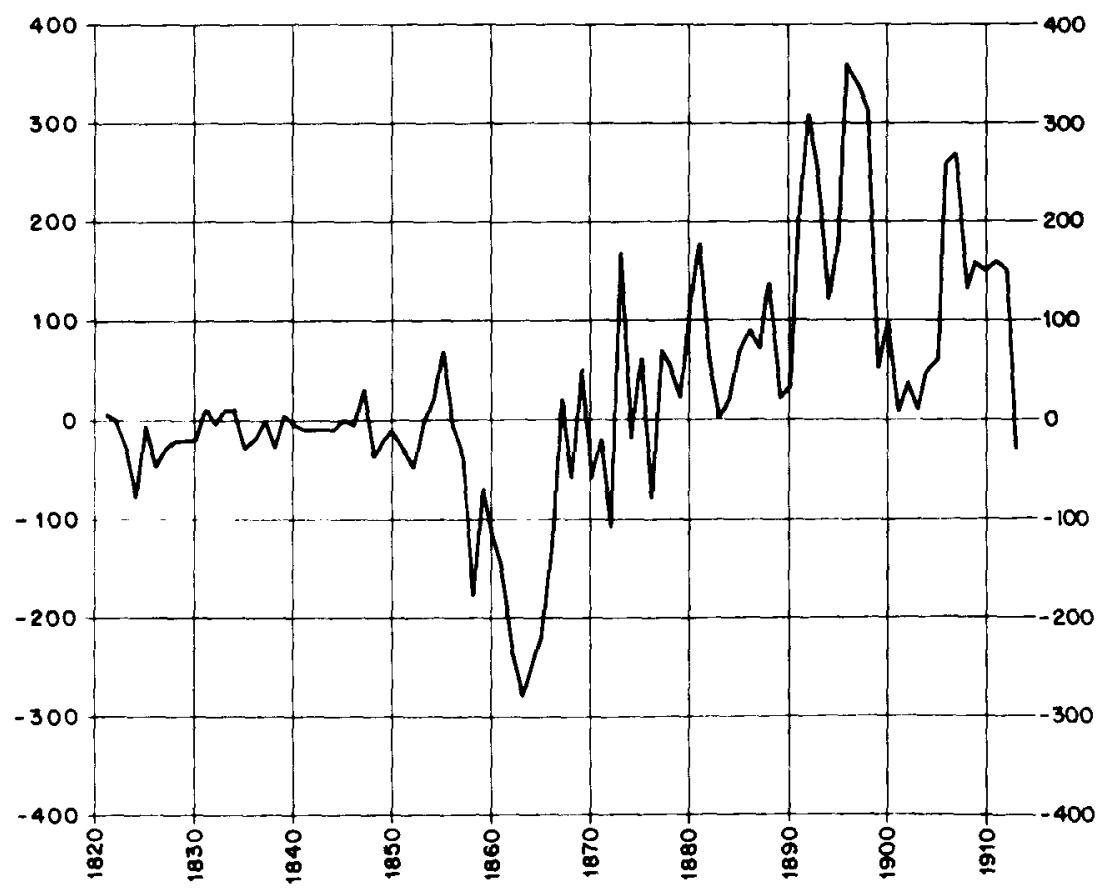

Géanse los gráficos 8 y 9.

¿ E. Témime, A. Broder y G. Chastagneret (1982), pp. 88-93; Broder, Chastagneret y Témime (1985), pp. 86-88. 


\section{GRAFICO 9}

Saldo de la balanza comercial, 1821-1913 (10 pesetas corrientes)

_. Saldo estimado

..... Saldo oficial

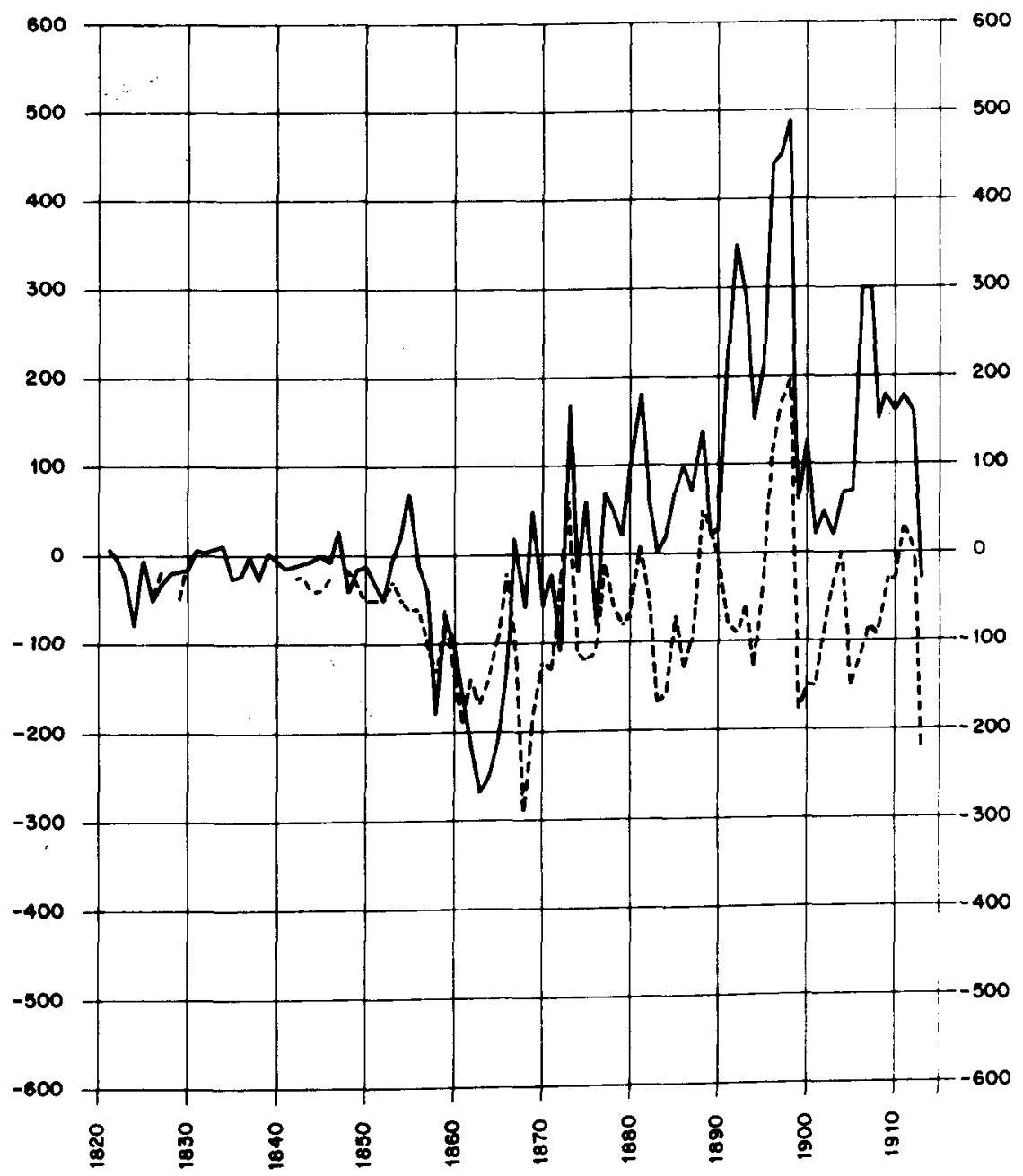


estimación tan sólo resultan 73,4 millones de pesos (366,8 millones de pesetas), esto es, 12 millones de pesetas como promedio ${ }^{70}$. Tras los saldos obtenidos para la balanza comercial en este ensayo, parece aventurado afirmar, como Témime, Broder y Chastagneret, que "el déficit creciente de los intercambios exteriores es uno de los elementos claves en la profunda deflación española de los años 1813-1855»"1.

Un fuerte déficit caracteriza a la fase de modernización acelerada de la economía española entre mediados de los años cincuenta y comienzos de los setenta. En él, las importaciones de materias primas (algodón, carbón) y bienes de equipo (material ferroviario) desempeñan un papel destacado ${ }^{72}$. Las inversiones extranjeras parecen haber financiado el déficit de la balanza de pagos por cuenta corriente durante este período ${ }^{73}$. Desde mediados de la década de 1870 hasta 1913 , el saldo estimado para la balanza de mercancías, como ya sospechara Gwinner, muestra una posición de superávit ${ }^{74}$. La explotación masiva de minerales y metales para la exportación, la demanda excepcional de vino durante los años ochenta con motivo de la epidemia de filoxera en Francia, la coyuntura exportadora a Cuba en los años de conflicto bélico previos a su independencia, junto a los aranceles proteccionistas de 1891 y 1906, explican la inversión de la tendencia deficitaria del período anterior ${ }^{75}$. Existen, no obstante, objeciones a estos resultados. Témime, Broder y Chastagneret, sobre la base, una vez más, del estudio de Broder, han afirmado:

«El excedente de la balanza comercial sólo es una apariencia contable. El comercio exterior, en términos de flujos financieros, es muy deficitatio" ${ }^{76}$.

Este juicio se apoya en el hecho de que

«sólo una pequeña parte del producto de las ventas de minerales y metales... vuelve a España... de 1880 a 1890 , únicamente del 25 al 30 por 100 del producto de las ventas" $\pi$.

La discusión se plantea, pues, en un plano de mayor complejidad técnica, que entronca con el debate en curso en los países en vías de desarrollo ${ }^{78}$. Se

10 Témime, Broder y Chastagneret (1983), p. 91

"I Ibidem, p. 93.

72 Cfr. Prados de la Escosura (1982 b), pp. $52-53$

${ }^{73} \mathrm{Cfr}$. A. Broder (1976). Los datos de este autor no están acompañados de las fuentes de las que han sido obtenidos y, en consecuencia, su validez se halla en entredicho.

${ }^{74}$ Gwinner (1973, pp. 288-289.

${ }^{75}$ Prados de la Escosura (1982 b), pp. 40-41, 43-45, 50-53; Maluquer de Motes (1974).

76 Témime, Broder y Chastagneret (1982), p. 135.

77 Ibidem, p. 135.

${ }^{78}$ Una síntesis del debate se ofrece en Prados de la Escosura (1986 b). 
trata de diferenciar entre el valor total exportado y el valor retenido en el país a cuyo subsuelo pertenecen los recursos, esto es, la retribución de los factores de producción nacionales asignados al sector exportador y las rentas obtenidas por el Estado. Existen diversas estimaciones de la proporción representada por el valor retenido dentro del valor total exportado para los principales minerales y metales que hacen posible realizar un cálculo tentativo de la magnitud del valor retenido en el valor total del conjunto de las exportaciones españolas ${ }^{79}$.

El cuadro 4 presenta medias decenales para las exportaciones totales y retenidas, así como los saldos que resultan de sustraer a cada una de ellas el valor de las importaciones ${ }^{80}$. Dos conclusiones se desprenden de este ejercicio. En primer lugar, el valor retenido constituye el 90 por 100 del valor total de las exportaciones acumuladas entre 1875 y 1913. Además, durante estos años, si bien su magnitud disminuye, los superávit persisten, con un saldo acumulado de 1.331,6 millones de pesetas, o 34,1 millones de promedio anual.

Resulta dffícil precisar cuál sería la posición de la balanza de pagos por cuenta corriente en las cuatro décadas que preceden a la Primera Guerra Mundial, pues se carece de información cuantitativa acerca de partidas de relieve

\section{CUADRO 4}

\section{Comercio exterior, $1875-1913\left(10^{6}\right.$ pesetas corrientes)}

(Medias decenales)

\begin{tabular}{|c|c|c|c|c|c|}
\hline \multirow[b]{3}{*}{$A \tilde{n} o s$} & \multicolumn{2}{|c|}{ EXPORTACIONES } & \multirow{2}{*}{$\begin{array}{c}\text { IMPORTA- } \\
\text { CIONES } \\
(3)\end{array}$} & \multirow{2}{*}{$\frac{\text { SALDO }}{(4)}$} & \multirow{2}{*}{$\frac{\text { COMERCIAL }}{(5)}$} \\
\hline & (1) & (2) & & & \\
\hline & $\begin{array}{l}\text { Valor } \\
\text { total }\end{array}$ & $\begin{array}{l}\text { Valor } \\
\text { retenido }\end{array}$ & & {$[(1)-(2)]$} & {$[(1)-(3)]$} \\
\hline $\begin{array}{lllll}1875-1884 & \ldots & \ldots & \ldots & \ldots \\
1885-1894 & \ldots & \ldots & \ldots & \ldots \\
1895-1904 & \ldots & \ldots & \ldots & \ldots \\
1905-1913 & \ldots & \ldots & \ldots & \ldots\end{array}$ & $\begin{array}{r}646,4 \\
866,5 \\
1.187,5 \\
1.330,4\end{array}$ & $\begin{array}{r}587.2 \\
797,4 \\
1.054,1 \\
1.172,6\end{array}$ & $\begin{array}{r}595,0 \\
721,4 \\
994,0 \\
1.167,2\end{array}$ & $\begin{array}{l}51,4 \\
145,1 \\
193,5 \\
163,2\end{array}$ & $\begin{array}{r}7,8 \\
76,0 \\
60,1 \\
5,4\end{array}$ \\
\hline
\end{tabular}

FuENTES: Apéndice, cuadro AP-3, y texto.

${ }^{79}$ Estas estimaciones se encuentran recogidas en Prados de la Escosura ( $1986 b$ ).

20 La diferencia entre las exportaciones retenidas y las importaciones no refleja, en sentido estricto, ni el saldo de la balanza de mercancías ni el saldo de la balanza de pagos por cuenta corriente, pues incluye, de manera arbitraria, algunos componentes de la balanza de servicios únicamente. Cfr. Prados de la Escosura (1986 b). 


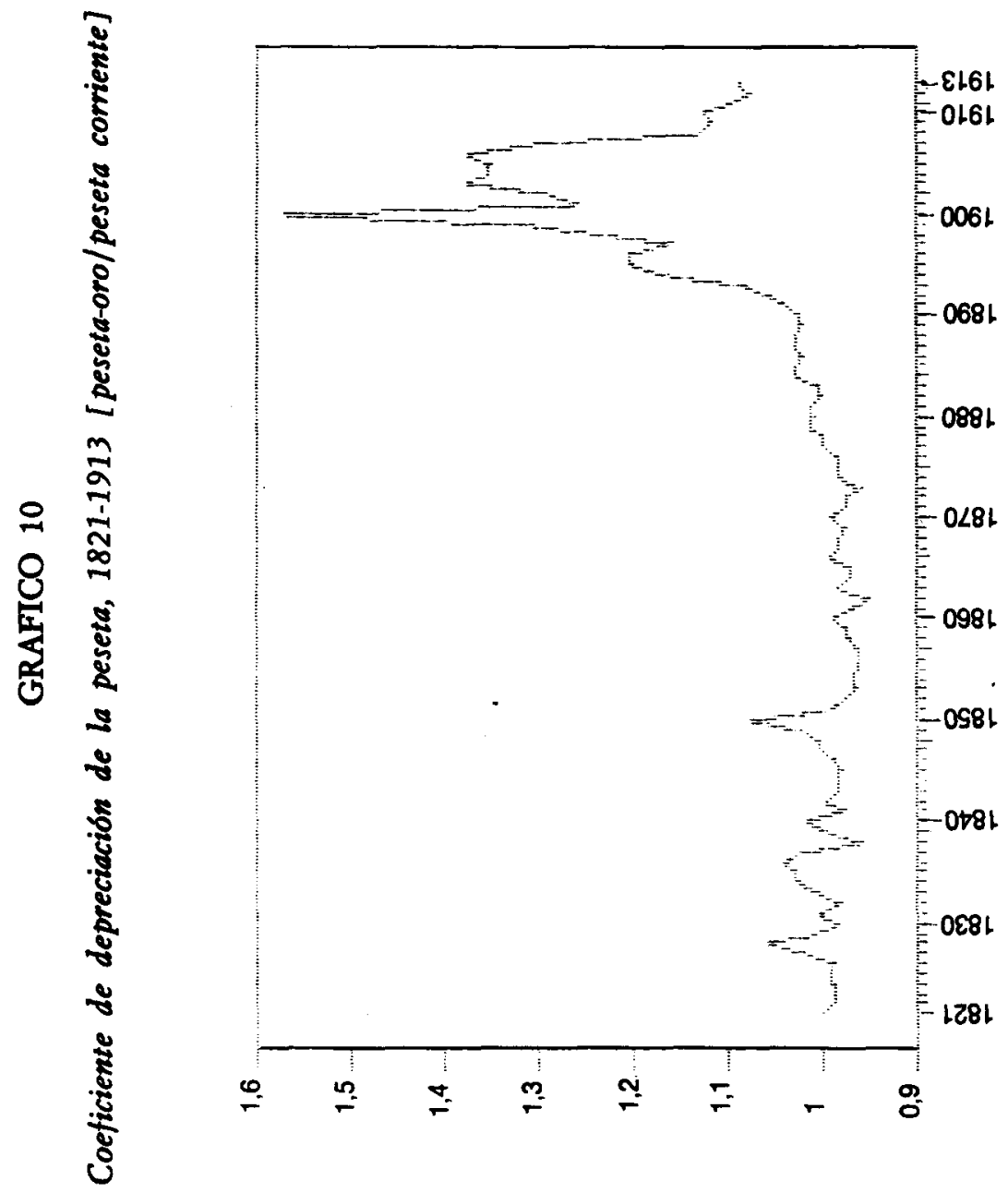


como los intereses y dividendos correspondientes a los capitales extranjeros invertidos en España o las remesas de emigrantes en América Latina. Puede sugerirse, sin embargo, que los resultados serían menos favorables para la balanza de pagos por cuenta corriente que para la balanza de mercancías. No obstante, tras la discusión llevada a cabo, parece plausible suponer que no se corresponderían con los que apuntan tanto la historiografía tradicional, inspirada en las series oficiales de comercio exterior, como los que sugiere el estudio de Broder. 


\section{APENDICE}

\section{Estadisticas extranjeras}

a) Comercio hispano-británico (1821-1913):

- Prados de la Escosura (1984).

b) Comercio hispano-francés (1821-1913):

- Statistique Générale de la France. Commerce extérieur (París, 1838), I vol., 1821-1836.

- Tableaux du commerce général el de la navigation de la France, 1837-1913.

- Statistique Générale de la France. Annuaire Statistique, 33 vol., 1913.

c) Comercio hispano-norteamericano (1821-1913):

- Statistical Tables Exbibiting the Commerce of the United States with European Countries from 1790 to 1890 (Washington, 1893), 1821-1890.

- Statistical Abstract(s) of the United States, 1891-1913.

d) Comercio hispano-belga (1860-1913) y comercio hispano-alemán (1882-1913):

- Statistical Abstract(s) for... Foreign Countries, hasta 1912.

- League of Nations (1924), para 1913.

\section{CUADRO AP.1}

Exportaciones: diferencias relativas de las muestras, 1850-1913 (\%)

$$
\left(100 \times \frac{\text { Valor oficial } \_ \text {Valor estimado }}{\text { Valor estimado }}\right)
$$

\begin{tabular}{|c|c|c|c|c|c|}
\hline Años & Mercancias & Paises & Años & Mercancias & Paises \\
\hline $1850 \ldots \ldots \ldots$ & $-27,6$ & $-25,4$ & $1866 \ldots \ldots$ & $-10,2$ & 4,8 \\
\hline $1851 \ldots \ldots \ldots$ & $-26,8$ & $-20 ; 9$ & $1867 \ldots$ & $-24,2$ & $-22,6$ \\
\hline $1852 \ldots \ldots \ldots$ & $-14,1$ & $-0,6$ & $1868 \ldots \ldots \ldots$ & $-31,7$ & $-28,8$ \\
\hline $1853 \ldots \ldots \ldots$ & $-12,5$ & 10,5 & $1869 \ldots \ldots \ldots$ & $-30,6$ & $-38,6$ \\
\hline $1854 \ldots \ldots \ldots$ & $-5,5$ & 6,2 & $\ldots \ldots$ & $-31,7$ & 18,6 \\
\hline $1855 \ldots \ldots \ldots$ & $-3,9$ & 1,1 & $\ldots \ldots \ldots$ & 1,0 & 0,6 \\
\hline $1856 \ldots \ldots \ldots$ & $-13,9$ & $-17,1$ & $\ldots \ldots \ldots$ & $-1,6$ & 2,9 \\
\hline $1857 \ldots \ldots \ldots$ & $-19,3$ & $-13,1$ & $\ldots \ldots \ldots$ & $-4,3$ & 0,5 \\
\hline $1858 \ldots \ldots \ldots$ & $-4,8$ & 19,0 & 1874 . & $-7,9$ & $-8,1$ \\
\hline $1859 \ldots \ldots \ldots$ & $-7,4$ & 3,8 & 1875 & 0,3 & $-16,1$ \\
\hline ...... & $-9,7$ & 0,7 & $1876 \ldots \ldots \ldots$ & $-9,1$ & $-1,6$ \\
\hline $1861 \ldots \ldots \ldots$ & $-0,8$ & 4,1 & $1877 \ldots \ldots \ldots$ & $-9,3$ & $-9,4$ \\
\hline $1862 \ldots \ldots \ldots$ & $-0,1$ & 12,8 & $1878 \ldots \ldots \ldots$ & $-4,1$ & $-10,4$ \\
\hline $1863 \ldots \ldots \ldots$ & $-5,9$ & 3,5 & $1879 \ldots \ldots \ldots$ & 9,8 & $-2,9$ \\
\hline $1864 \ldots \ldots \ldots$ & $-8,1$ & 10,2 & $1880 \ldots \ldots \ldots$ & 6,6 & $-3,7$ \\
\hline $1865 \ldots \ldots \ldots$ & $-3,0$ & 23,1 & $1881 \ldots \ldots \ldots$ & 7,5 & $-2,8$ \\
\hline
\end{tabular}




\section{CUADRO AP-1 (Continuación)}

Exportaciones: diferencias relativas de las muestras, 1850-1913 (\%)

$$
\left(100 \times \frac{\text { Valor oficial }- \text { Valor estimado }}{\text { Valor estimado }}\right)
$$

\begin{tabular}{|c|c|c|c|c|c|}
\hline$A \bar{n} o s$ & Mercancias & Paises & $A \tilde{n} o s$ & Mercancias & Países \\
\hline $\begin{array}{llll}1882 & \ldots & \ldots & \ldots \\
1883 & \ldots & \ldots & \ldots \\
1884 & \ldots & \ldots & \ldots \\
1885 & \ldots & \ldots & \ldots \\
1886 & \ldots & \ldots & \ldots \\
1887 & \ldots & \ldots & \ldots \\
1888 & \ldots & \ldots & \ldots \\
1889 & \ldots & \ldots & \ldots \\
1890 & \ldots & \ldots & \ldots \\
1891 & \ldots & \ldots & \ldots \\
1892 & \ldots & \ldots & \ldots \\
1893 & \ldots & \ldots & \ldots \\
1894 & \ldots & \ldots & \ldots \\
1895 & \ldots & \ldots & \ldots \\
1896 & \ldots & \ldots & \ldots \\
1897 & \ldots & \ldots & \ldots\end{array}$ & $\begin{array}{r}6,5 \\
-0,6 \\
-11,9 \\
-7,8 \\
-19,4 \\
-2,8 \\
-7,1 \\
2,4 \\
-2,7 \\
-6,4 \\
15,1 \\
-11,1 \\
-17,3 \\
-15,5 \\
-10,9 \\
-16,1\end{array}$ & $\begin{array}{r}-4,9 \\
-3,8 \\
-4,2 \\
-4,2 \\
-11,7 \\
-5,0 \\
-6,6 \\
5,3 \\
7,0 \\
-3,1 \\
-23,9 \\
-12,4 \\
-25,5 \\
-12,0 \\
-17,8 \\
-20,3\end{array}$ & $\begin{array}{llll}1898 & \ldots & \ldots & \ldots \\
1899 & \ldots & \ldots & \ldots \\
1900 & \ldots & \ldots & \ldots \\
1901 & \ldots & \ldots & \ldots \\
1902 & \ldots & \ldots & \ldots \\
1903 & \ldots & \ldots & \ldots \\
1904 & \ldots & \ldots & \ldots \\
1905 & \ldots & \ldots & \ldots \\
1906 & \ldots & \ldots & \ldots \\
1907 & \ldots & \ldots & \ldots \\
1908 & \ldots & \ldots & \ldots \\
1909 & \ldots & \ldots & \ldots \\
1910 & \ldots & \ldots & \ldots \\
1911 & \ldots & \ldots & \ldots \\
1912 & \ldots & \ldots & \ldots \\
1913 & \ldots & \ldots & \ldots\end{array}$ & $\begin{array}{l}-36,3 \\
-19,2 \\
-22,5 \\
-22,1 \\
-12,7 \\
-11,4 \\
-12,1 \\
-9,4 \\
-18,9 \\
-24,5 \\
-25,6 \\
-22,9 \\
-24,2 \\
-26,1 \\
-27,7 \\
-30,6\end{array}$ & $\begin{array}{l}-30,1 \\
-20,6 \\
-31,6 \\
-31,8 \\
-25,2 \\
-26,5 \\
-23,7 \\
-22,8 \\
-29,7 \\
-27,0 \\
-16,9 \\
-10,4 \\
-14,3 \\
-21,1 \\
-24,1 \\
-23,0\end{array}$ \\
\hline
\end{tabular}

Fuentes: Véase el texto. 


\section{CUADRO AP-2}

Importaciones: diferencias relativas de las muestras, $1850-1913$ (\%)

$$
\left(100 \times \frac{\text { Valor oficial }- \text { Valor estimado }}{\text { Valor oficial }}\right)
$$

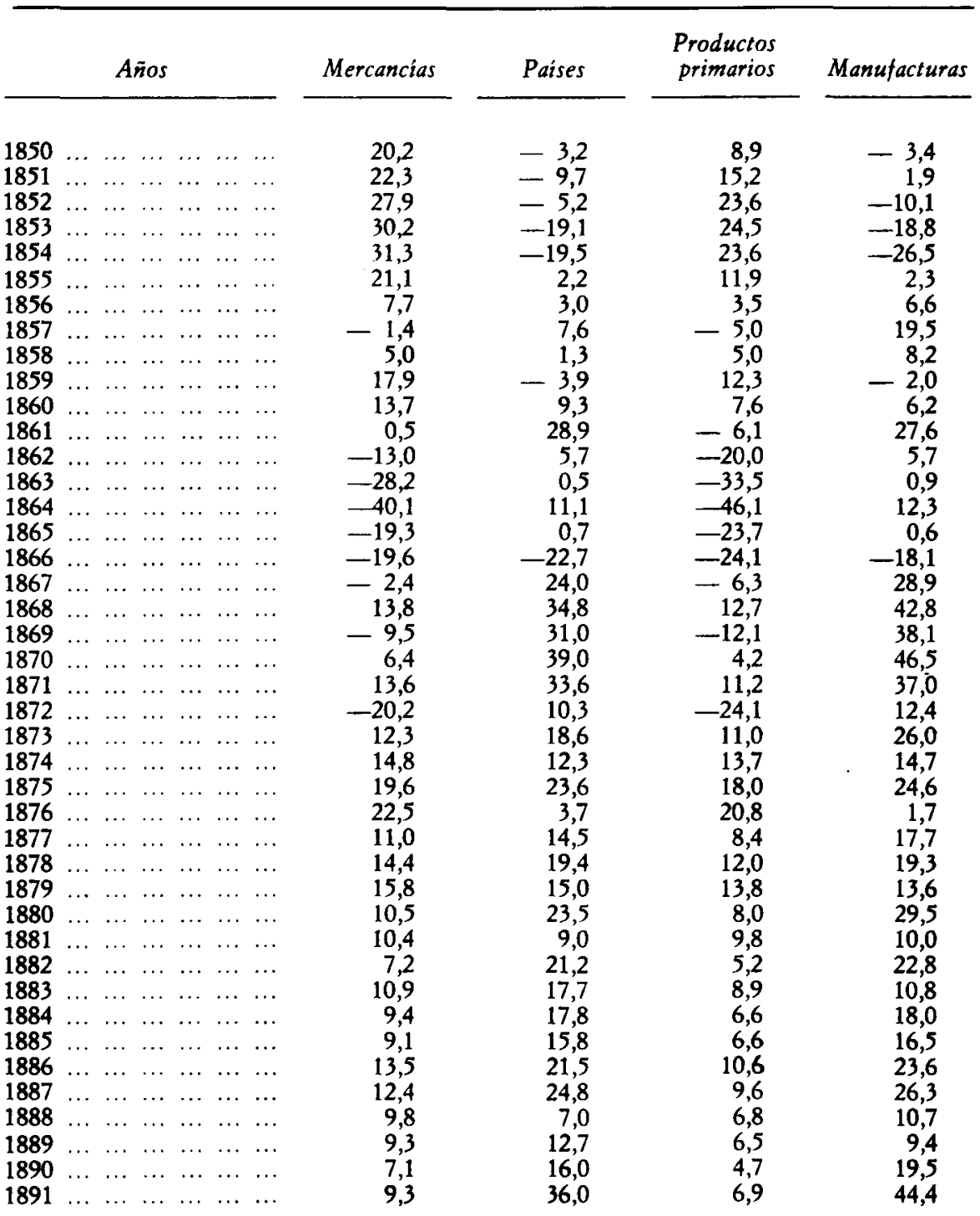




\section{CUADRO AP-2 (Continuación)}

Importaciones: diferencias relativas de las muestras, 1850-1913 (\%)

$$
\left(100 \times \frac{\text { Valor oficial }- \text { Valor estimado }}{\text { Valor oficial }}\right)
$$

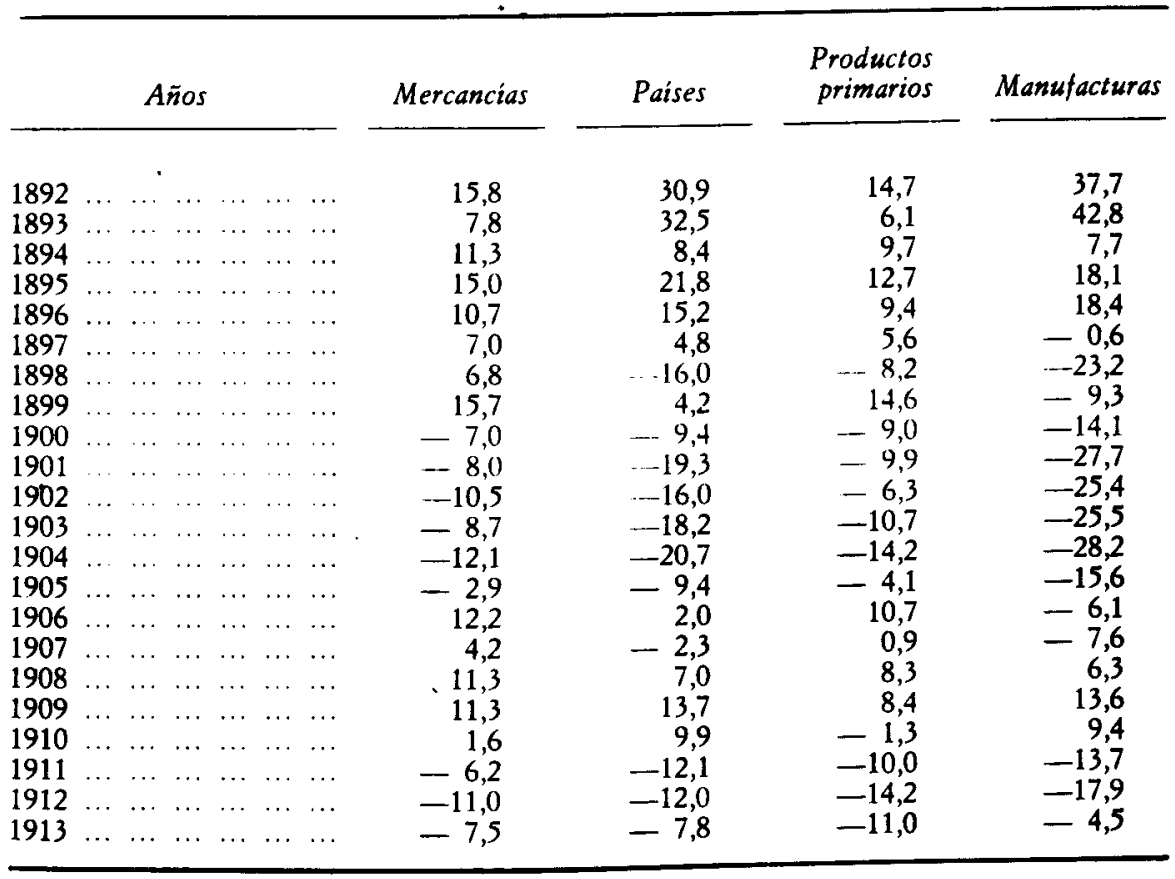

Fuentes: Véase el texto. 


\section{CUADRO AP-3}

La balanza de mercancías de España, 1821-1913

\begin{tabular}{|c|c|c|c|c|c|c|c|c|c|c|}
\hline & & & & & & pesetas & oro) & $\left(10^{\circ} \mathrm{F}\right.$ & setas cor & ientes) \\
\hline & $A \tilde{n} o s$ & & & & $\begin{array}{c}(1) \\
\text { Export. } \\
\text { t.o.b. }\end{array}$ & $\begin{array}{c}(2) \\
\text { Import. } \\
\text { c.i.f. }\end{array}$ & $\begin{array}{c}(3) \\
\text { Saldo } \\
(1)-(2)\end{array}$ & $\begin{array}{c}(4) \\
\text { Export. } \\
\text { f.o.b. }\end{array}$ & $\begin{array}{c}(5) \\
\text { Import. } \\
\text { c.i.f. }\end{array}$ & $\begin{array}{c}\text { (6) } \\
\text { Saldo } \\
(4)-(5)\end{array}$ \\
\hline $\begin{array}{ll}1821 & \ldots \\
1822 & \ldots \\
1823 & \ldots \\
1824 & \ldots \\
1825 & \ldots \\
1826 & \ldots \\
1827 & \ldots \\
1828 & \ldots \\
1829 & \ldots\end{array}$ & $\begin{array}{ll}\ldots & \ldots \\
\ldots & \ldots \\
\ldots & \ldots \\
\ldots & \ldots \\
\ldots & \ldots \\
\ldots & \ldots \\
\ldots & \ldots \\
\ldots & \ldots \\
\ldots & \ldots \\
\ldots\end{array}$ & $\begin{array}{l}\ldots \\
\ldots \\
\ldots \\
\ldots \\
\ldots \\
\ldots \\
\ldots \\
\ldots \\
\ldots\end{array}$ & $\begin{array}{l}\ldots \\
\ldots \\
\ldots \\
\ldots \\
\ldots \\
\ldots \\
\ldots \\
\ldots \\
\ldots\end{array}$ & $\begin{array}{l}\cdots \\
\ldots \\
\ldots \\
\ldots \\
\ldots \\
\ldots \\
\ldots \\
\ldots \\
\cdots\end{array}$ & $\begin{array}{r}109,6 \\
110,6 \\
89,3 \\
89,9 \\
140,3 \\
83,4 \\
98,9 \\
104,9 \\
115,1\end{array}$ & $\begin{array}{l}105,2 \\
111,3 \\
114,4 \\
169,1 \\
143,8 \\
134,3 \\
130,0 \\
123,8 \\
132,4\end{array}$ & $\begin{array}{r}4,4 \\
-\quad 0,7 \\
-25,5 \\
-\quad 79,2 \\
-\quad 3,5 \\
-\quad 50,9 \\
-\quad 32,0 \\
-18,9 \\
-17,3\end{array}$ & $\begin{array}{r}108,1 \\
109,1 \\
87,9 \\
89,1 \\
138,1 \\
85,2 \\
104,5 \\
106,0 \\
113,1\end{array}$ & $\begin{array}{l}103,8 \\
109,8 \\
112,6 \\
167,6 \\
141,6 \\
137,2 \\
137,4 \\
125,1 \\
130,1\end{array}$ & $\begin{array}{r}4,3 \\
-\quad 0,7 \\
-\quad 24,7 \\
-78,5 \\
-\quad 3,5 \\
-\quad 52,0 \\
-32,9 \\
-\quad 19,1 \\
-17,0\end{array}$ \\
\hline $\begin{array}{ll}1830 & \ldots \\
1831 & \ldots \\
1832 & \ldots \\
1833 & \ldots \\
1834 & \ldots \\
1835 & \ldots \\
1836 & \ldots \\
1837 & \ldots \\
1838 & \ldots \\
1839 & \ldots\end{array}$ & $\begin{array}{ll}\ldots & \ldots \\
\ldots & \ldots \\
\ldots & \ldots \\
\ldots & \ldots \\
\ldots & \ldots \\
\ldots & \ldots \\
\ldots & \ldots \\
\ldots & \ldots \\
\ldots & \ldots \\
\ldots & \ldots\end{array}$ & $\begin{array}{l}\ldots \\
\ldots \\
\ldots \\
\ldots \\
\ldots \\
\ldots \\
\ldots \\
\ldots \\
\ldots \\
\ldots\end{array}$ & $\begin{array}{l}\ldots \\
\ldots \\
\ldots \\
\ldots \\
\ldots \\
\ldots \\
\ldots \\
\ldots \\
\ldots \\
\ldots\end{array}$ & $\begin{array}{l}\cdots \\
\cdots \\
\cdots \\
\cdots \\
\ldots \\
\cdots \\
\cdots \\
\cdots \\
\cdots \\
\cdots\end{array}$ & $\begin{array}{r}98,5 \\
125,2 \\
89,2 \\
131,9 \\
115,0 \\
110,5 \\
141,1 \\
135,1 \\
115,5 \\
148,8\end{array}$ & $\begin{array}{r}115,3 \\
115,6 \\
92,4 \\
123,2 \\
103,0 \\
136,8 \\
164,3 \\
134,7 \\
142,0 \\
145,4\end{array}$ & $\begin{array}{r}16,8 \\
9,6 \\
-\quad 3,2 \\
8,7 \\
12,0 \\
-26,3 \\
-23,2 \\
0,4 \\
-26,5 \\
3,4\end{array}$ & $\begin{array}{r}98,8 \\
122,2 \\
89,5 \\
135,0 \\
118,2 \\
115,1 \\
144,5 \\
129,4 \\
114,8 \\
151,3\end{array}$ & $\begin{array}{r}115,7 \\
112,9 \\
92,7 \\
126,1 \\
105,9 \\
142,4 \\
168,3 \\
129,0 \\
141,1 \\
147,8\end{array}$ & $\begin{array}{r}16,9 \\
9,3 \\
-\quad 3,2 \\
8,9 \\
12,3 \\
-27,3 \\
-23,8 \\
0,4 \\
-26,3 \\
3,5\end{array}$ \\
\hline $\begin{array}{ll}1840 & \ldots \\
1841 & \ldots \\
1842 & \ldots \\
1843 & \ldots \\
1844 & \ldots \\
1845 & \ldots \\
1846 & \ldots \\
1847 & \ldots \\
1848 & \ldots \\
1849 & \ldots\end{array}$ & $\begin{array}{ll}\ldots & \ldots \\
\ldots & \cdots \\
\ldots & \cdots \\
\ldots & \cdots \\
\ldots & \ldots \\
\ldots & \cdots \\
\ldots & \cdots \\
\ldots & \ldots \\
\ldots & \cdots \\
\ldots & \cdots\end{array}$ & $\begin{array}{l}\ldots \\
\ldots \\
\ldots \\
\ldots \\
\ldots \\
\ldots \\
\ldots \\
\ldots \\
\ldots \\
\ldots\end{array}$ & $\begin{array}{l}\ldots \\
\ldots \\
\ldots \\
\ldots \\
\ldots \\
\ldots \\
\ldots \\
\ldots \\
\ldots \\
\ldots\end{array}$ & $\begin{array}{l}\cdots \\
\cdots \\
\cdots \\
\cdots \\
\cdots \\
\cdots \\
\cdots \\
\cdots \\
\cdots \\
\cdots\end{array}$ & $\begin{array}{l}144,2 \\
124,9 \\
140,5 \\
127,7 \\
154,3 \\
154,0 \\
168,4 \\
192,9 \\
120,2 \\
138,6\end{array}$ & $\begin{array}{l}146,9 \\
139,0 \\
150,6 \\
136,1 \\
160,4 \\
153,9 \\
171,5 \\
163,1 \\
158,0 \\
154,7\end{array}$ & $\begin{array}{r}2,7 \\
-\quad 14,1 \\
-\quad 10,1 \\
-\quad 8,4 \\
-\quad 6,1 \\
0,1 \\
-\quad 3,1 \\
29,8 \\
-37,8 \\
-\quad 16,1\end{array}$ & $\begin{array}{l}140,3 \\
124,0 \\
137,9 \\
125,3 \\
151,2 \\
151,8 \\
168,8 \\
195,1 \\
129,3 \\
137,0\end{array}$ & $\begin{array}{l}142,9 \\
138,0 \\
147,8 \\
133,6 \\
157,1 \\
151,7 \\
171,9 \\
165,0 \\
169,9 \\
152,9\end{array}$ & $\begin{array}{r}2,6 \\
-\quad 14,0 \\
-\quad 9,9 \\
=\quad 8,3 \\
-\quad 5,9 \\
0,1 \\
-\quad 3,1 \\
30,1 \\
-40,6 \\
-15,6\end{array}$ \\
\hline $\begin{array}{ll}1850 & \ldots \\
1851 & \ldots \\
1852 & \ldots \\
1853 & \ldots \\
1854 & \ldots \\
1855 & \ldots \\
1856 & \ldots \\
1857 & \ldots \\
1858 & \ldots \\
1859 & \ldots\end{array}$ & $\begin{array}{ll}\ldots & \ldots \\
\ldots & \cdots \\
\ldots & \ldots \\
\ldots & \ldots \\
\ldots & \ldots \\
\ldots & \cdots \\
\ldots & \cdots \\
\ldots & \ldots \\
\ldots & \ldots \\
\ldots & \ldots \\
& \ldots\end{array}$ & $\begin{array}{l}\ldots \\
\ldots \\
\ldots \\
\ldots \\
\ldots \\
\ldots \\
\ldots \\
\ldots\end{array}$ & $\begin{array}{l}\ldots \\
\ldots \\
\ldots \\
\ldots \\
\ldots \\
\ldots \\
\ldots \\
\ldots \\
\ldots \\
\ldots\end{array}$ & $\begin{array}{l}\cdots \\
\cdots \\
\cdots \\
\cdots \\
\cdots \\
\cdots \\
\cdots \\
\cdots \\
\cdots \\
\cdots\end{array}$ & $\begin{array}{l}168,5 \\
150,4 \\
141,1 \\
195,9 \\
240,8 \\
335,4 \\
333,3 \\
345,0 \\
206,4 \\
254,6\end{array}$ & $\begin{array}{l}178,6 \\
175,6 \\
191,3 \\
200,2 \\
223,7 \\
267,4 \\
341,8 \\
386,0 \\
384,7 \\
326,5\end{array}$ & $\begin{array}{r}10,1 \\
-\quad 25,2 \\
-\quad 50,2 \\
-\quad 4,3 \\
17,1 \\
68,0 \\
-\quad 8,5 \\
-41,0 \\
-178,3 \\
-71,9\end{array}$ & $\begin{array}{l}163,9 \\
144,8 \\
136,5 \\
188,0 \\
131,3 \\
322,8 \\
323,3 \\
336,3 \\
203,9 \\
247,2\end{array}$ & $\begin{array}{l}173,7 \\
169,1 \\
185,0 \\
192,1 \\
214,9 \\
257,3 \\
331,6 \\
376,2 \\
380,1 \\
317,0\end{array}$ & $\begin{array}{r}9,8 \\
-\quad 24,3 \\
-\quad 48,5 \\
-\quad 4,1 \\
16,4 \\
65,5 \\
-\quad 8,3 \\
-39,9 \\
-176,2 \\
-\quad 69,8\end{array}$ \\
\hline
\end{tabular}


CUADRO AP-3 (Continuación)

La balanza de mercancias de España, 1821-1913

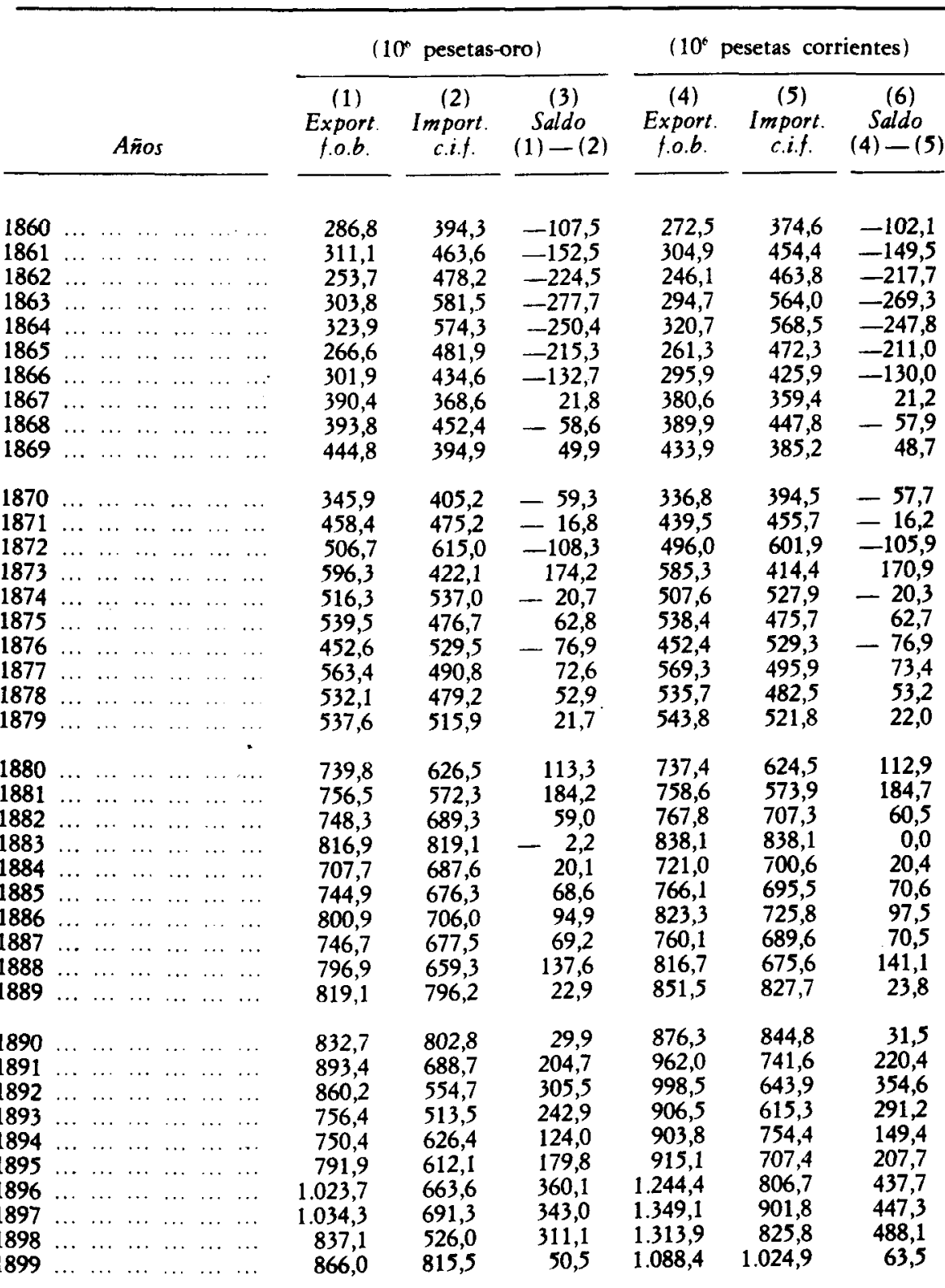




\section{CUADRO AP-3 (Continuación)}

La balanza de mercancias de España, 1821-1913

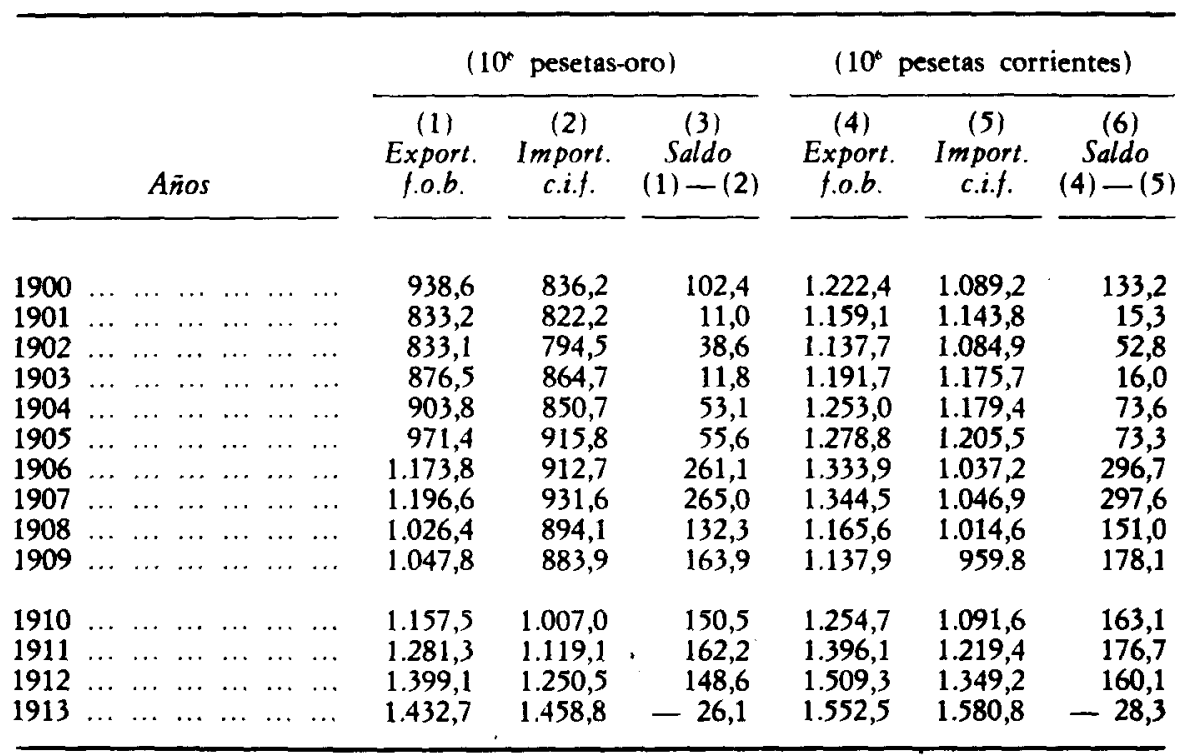

FuEnTEs: Véase el texto 


\section{CUADRO AP-4}

Importaciones netas c.i.f. (10 $10^{6}$ pesetas-oro), 1821-1849

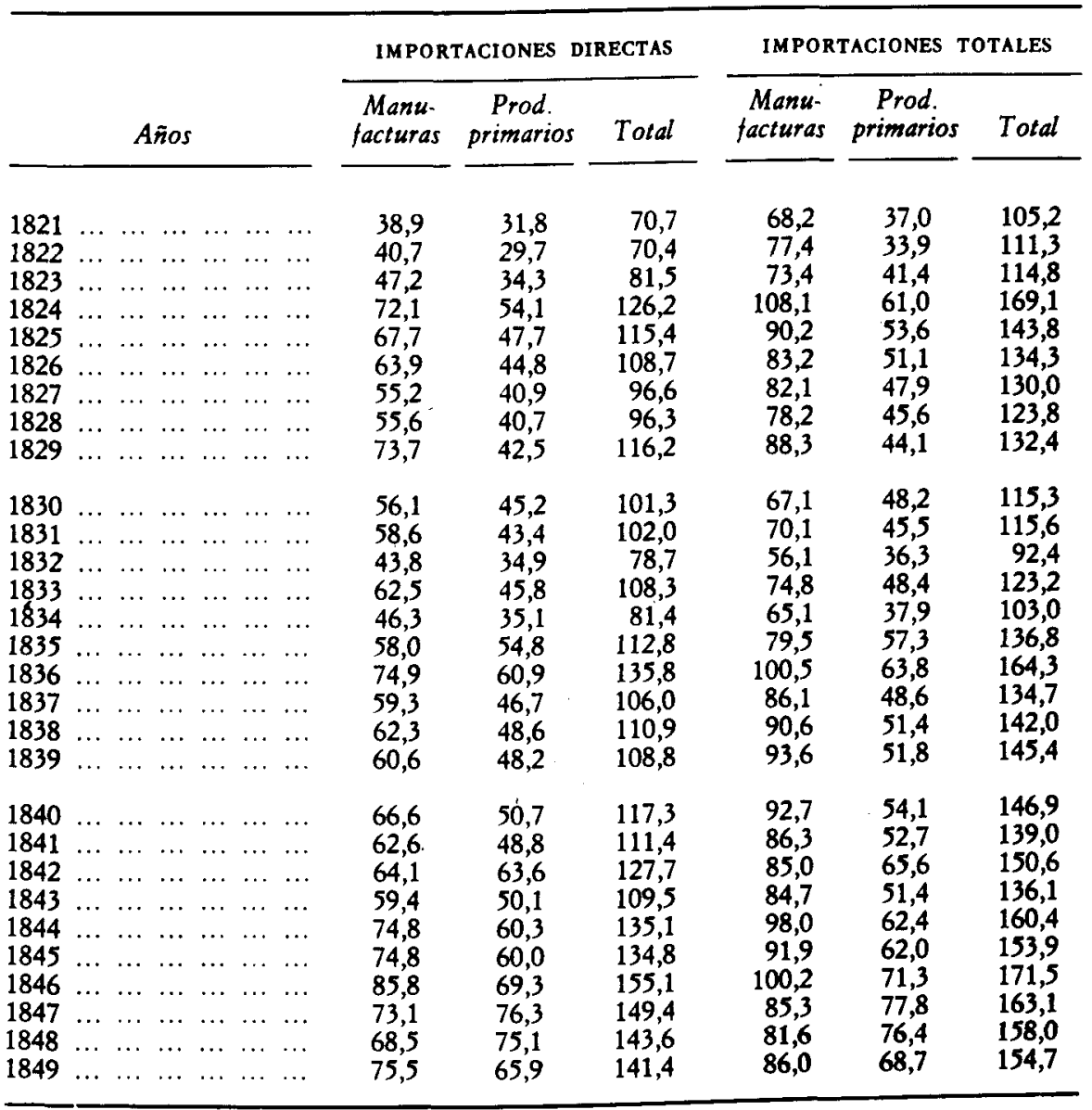

Fuentes: Véase el texto. 


\section{CUADRO AP-5}

Importaciones netas c.i.f. (10 $10^{6}$ pesetas-oro), 1849-1913

\begin{tabular}{|c|c|c|c|c|c|c|c|c|}
\hline \multirow[b]{2}{*}{ Años } & \multicolumn{4}{|c|}{ IMPORTACIONES DIRECTAS } & \multicolumn{4}{|c|}{ IMPORTACIONES TOTALES } \\
\hline & $\begin{array}{l}\text { Manu- } \\
\text { facturas }\end{array}$ & $\begin{array}{c}\text { Ali- } \\
\text { mentos }\end{array}$ & $\begin{array}{c}\text { Materias } \\
\text { primas }\end{array}$ & Total & $\begin{array}{l}\text { Manu- } \\
\text { facturas }\end{array}$ & $\begin{array}{c}\text { Ali- } \\
\text { mentos }\end{array}$ & $\begin{array}{l}\text { Materias } \\
\text { primas }\end{array}$ & Total \\
\hline $\begin{array}{c}*_{1849} \\
1850 \\
1851 \\
1852 \\
1853 \\
1854 \\
1855 \\
1856 \\
1857 \\
1858 \\
1859\end{array}$ & $\begin{array}{r}75,5 \\
83,9 \\
81,6 \\
93,9 \\
106,0 \\
103,9 \\
121,7 \\
158,9 \\
171,7 \\
178,9 \\
161,5\end{array}$ & $\begin{array}{r}40,5 \\
47,1 \\
45,9 \\
52,1 \\
46,7 \\
59,8 \\
73,4 \\
91,3 \\
147,3 \\
110,9 \\
78,4\end{array}$ & $\begin{array}{l}25,4 \\
36,4 \\
35,2 \\
31,4 \\
30,4 \\
39,2 \\
51,1 \\
69,0 \\
47,5 \\
65,6 \\
67,8\end{array}$ & $\begin{array}{l}141,4 \\
167,4 \\
162,7 \\
177,4 \\
183,1 \\
202,9 \\
246,2 \\
319,2 \\
366,5 \\
355,4 \\
307,7\end{array}$ & $\begin{array}{r}86,0 \\
94,4 \\
93,8 \\
106,9 \\
122,3 \\
122,8 \\
141,6 \\
180,2 \\
189,0 \\
206,8 \\
179,4\end{array}$ & $\begin{array}{r}40,5 \\
47,1 \\
45,9 \\
52,1 \\
46,7 \\
59,8 \\
73,4 \\
91,3 \\
147,3 \\
110,9 \\
78,4\end{array}$ & $\begin{array}{l}28,2 \\
37,1 \\
35,9 \\
32,3 \\
31,2 \\
41,1 \\
52,4 \\
70,3 \\
49,7 \\
67,0 \\
68,7\end{array}$ & $\begin{array}{l}154,7 \\
178,6 \\
175,6 \\
191,3 \\
200,2 \\
223,7 \\
267,4 \\
341,8 \\
386,0 \\
384,7 \\
326,5\end{array}$ \\
\hline $\begin{array}{l}1860 \\
1861 \\
1862 \\
1863 \\
1864 \\
1865 \\
1866 \\
1867 \\
1868 \\
1869\end{array}$ & $\begin{array}{l}194,9 \\
243,4 \\
255,2 \\
309,7 \\
286,6 \\
249,3 \\
212,3 \\
185,1 \\
150,2 \\
174,9\end{array}$ & $\begin{array}{r}87,7 \\
91,2 \\
109,5 \\
133,4 \\
156,1 \\
123,3 \\
100,6 \\
84,0 \\
225,5 \\
111,1\end{array}$ & $\begin{array}{r}81,1 \\
99,7 \\
85,3 \\
102,4 \\
100,8 \\
79,8 \\
91,6 \\
75,4 \\
51,4 \\
80,7\end{array}$ & $\begin{array}{l}363,7 \\
434,3 \\
450,0 \\
545,5 \\
543,5 \\
452,4 \\
404,5 \\
344,5 \\
427,1 \\
366,7\end{array}$ & $\begin{array}{l}222,0 \\
270,6 \\
279,8 \\
341,8 \\
315,5 \\
276,9 \\
239,5 \\
204,6 \\
169,4 \\
195,6\end{array}$ & $\begin{array}{r}87,7 \\
91,2 \\
109,5 \\
133,4 \\
156,1 \\
123,3 \\
100,6 \\
84,0 \\
225,5 \\
111,1\end{array}$ & $\begin{array}{r}84,6 \\
101,8 \\
88,9 \\
106,3 \\
102,7 \\
81,7 \\
94,5 \\
80,0 \\
57,5 \\
88,2\end{array}$ & $\begin{array}{l}394,3 \\
463,6 \\
478,2 \\
581,5 \\
574,3 \\
481,9 \\
434,6 \\
368,6 \\
452,4 \\
394,9\end{array}$ \\
\hline $\begin{array}{l}1870 \\
1871 \\
1872 \\
1873 \\
1874 \\
1875 \\
1876 \\
1877 \\
1878 \\
1879\end{array}$ & $\begin{array}{l}177,8 \\
215,9 \\
229,8 \\
230,9 \\
277,1 \\
259,5 \\
298,8 \\
256,1 \\
256,2 \\
269,1\end{array}$ & $\begin{array}{r}87,1 \\
85,0 \\
129,8 \\
76,4 \\
75,8 \\
59,5 \\
73,1 \\
77,9 \\
81,4 \\
112,2\end{array}$ & $\begin{array}{r}108,2 \\
137,6 \\
212,4 \\
75,3 \\
146,2 \\
126,7 \\
124,8 \\
125,0 \\
112,3 \\
110,8\end{array}$ & $\begin{array}{l}373,1 \\
438,5 \\
572,0 \\
382,6 \\
499,1 \\
445,7 \\
496,7 \\
459,0 \\
449,9 \\
492,1\end{array}$ & $\begin{array}{l}198,5 \\
241,0 \\
259,0 \\
262,9 \\
307,2 \\
287,0 \\
326,7 \\
279,0 \\
276,6 \\
288,3\end{array}$ & $\begin{array}{r}87,1 \\
85,0 \\
129,8 \\
76,4 \\
75,8 \\
59,5 \\
73,1 \\
77,9 \\
81,4 \\
112,2\end{array}$ & $\begin{array}{r}119,6 \\
149,2 \\
226,2 \\
82,8 \\
154,0 \\
130,2 \\
129,7 \\
133,2 \\
121,2 \\
115,4\end{array}$ & $\begin{array}{l}405,2 \\
475,2 \\
615,0 \\
422,1 \\
537,0 \\
476,7 \\
529,5 \\
490,8 \\
479,2 \\
515,9\end{array}$ \\
\hline $\begin{array}{l}1880 \\
1881 \\
1882 \\
1883 \\
1884 \\
1885 \\
1886 \\
1887 \\
1888 \\
1889\end{array}$ & $\begin{array}{l}283,3 \\
291,1 \\
340,4 \\
396,1 \\
366,7 \\
340,5 \\
344,9 \\
311,7 \\
337,8 \\
408,1\end{array}$ & $\begin{array}{l}137,2 \\
111,7 \\
171,6 \\
204,4 \\
135,6 \\
161,7 \\
186,3 \\
189,6 \\
147,0 \\
139,1\end{array}$ & $\begin{array}{l}176,7 \\
139,0 \\
151,9 \\
196,2 \\
161,4 \\
151,7 \\
153,8 \\
148,6 \\
151,6 \\
224,0\end{array}$ & $\begin{array}{l}597,2 \\
541,8 \\
663,9 \\
796,7 \\
663,7 \\
653,9 \\
685,0 \\
649,9 \\
636,4 \\
771,2\end{array}$ & $\begin{array}{l}304,7 \\
311,8 \\
361,2 \\
416,4 \\
386,8 \\
358,6 \\
362,8 \\
335,2 \\
358,6 \\
431,3\end{array}$ & $\begin{array}{l}137,2 \\
111,7 \\
171,6 \\
204,4 \\
135,6 \\
161,7 \\
186,3 \\
189,6 \\
147,0 \\
139,1\end{array}$ & $\begin{array}{l}184,6 \\
148,8 \\
156,5 \\
198,3 \\
165,2 \\
156,0 \\
156,9 \\
152,7 \\
153,7 \\
225,8\end{array}$ & $\begin{array}{l}626,5 \\
572,3 \\
689,3 \\
819,1 \\
687,6 \\
676,3 \\
706,0 \\
677,5 \\
659,3 \\
796,2\end{array}$ \\
\hline
\end{tabular}




\section{CUADRO AP-5 (Continuación)}

Importaciones netas c.if. (106 pesetas-oro), 1849-1913

\begin{tabular}{|c|c|c|c|c|c|c|c|c|}
\hline \multirow[b]{2}{*}{ Años } & \multicolumn{4}{|c|}{ IMPORTACIONES DIRECTAS } & \multicolumn{4}{|c|}{ IMPORTACIONES TOTALES } \\
\hline & $\begin{array}{c}\text { Manu- } \\
\text { facturas }\end{array}$ & $\begin{array}{c}\text { Ali. } \\
\text { mentos }\end{array}$ & $\begin{array}{l}\text { Materias } \\
\text { primas }\end{array}$ & Total & $\begin{array}{c}\text { Manu- } \\
\text { facturas }\end{array}$ & $\begin{array}{c}\text { Ali- } \\
\text { mentos }\end{array}$ & $\begin{array}{c}\text { Materias } \\
\text { primas }\end{array}$ & Total \\
\hline $\begin{array}{l}1890 \\
1891 \\
1892 \\
1893 \\
1894 \\
1895 \\
1896 \\
1897 \\
1898 \\
1899\end{array}$ & $\begin{array}{l}403,4 \\
307,1 \\
237,7 \\
171,1 \\
275,4 \\
269,3 \\
272,6 \\
254,8 \\
222,5 \\
379,8\end{array}$ & $\begin{array}{r}165,9 \\
139,4 \\
116,2 \\
138,9 \\
145,3 \\
126,7 \\
151,8 \\
150,0 \\
96,1 \\
161,3\end{array}$ & $\begin{array}{l}209,1 \\
220,1 \\
183,2 \\
184,5 \\
189,0 \\
201,0 \\
223,4 \\
269,2 \\
188,5 \\
252,7\end{array}$ & $\begin{array}{l}778,4 \\
666,6 \\
537,1 \\
494,5 \\
609,7 \\
597,0 \\
647,8 \\
674,0 \\
507,1 \\
793,8\end{array}$ & $\begin{array}{l}426,0 \\
327,5 \\
253,8 \\
188,6 \\
290,4 \\
283,1 \\
287,0 \\
270,9 \\
240,6 \\
399,7\end{array}$ & $\begin{array}{r}165,9 \\
139,4 \\
116,2 \\
138,9 \\
145,3 \\
126,7 \\
151,8 \\
150,0 \\
96,1 \\
161,3\end{array}$ & $\begin{array}{l}210,9 \\
221,8 \\
184,7 \\
186,0 \\
190,7 \\
203,3 \\
224,8 \\
270,4 \\
189,3 \\
254,5\end{array}$ & $\begin{array}{l}802,8 \\
688,7 \\
554,7 \\
513,5 \\
626,4 \\
612,1 \\
663,6 \\
691,3 \\
526,0 \\
815,5\end{array}$ \\
\hline $\begin{array}{l}1900 \\
1901 \\
1902 \\
1903 \\
1904 \\
1905 \\
1906 \\
1907 \\
1908 \\
1909\end{array}$ & $\begin{array}{l}381,1 \\
364,6 \\
359,3 \\
378,2 \\
345,4 \\
326,7 \\
366,5 \\
377,8 \\
379,8 \\
376,9\end{array}$ & $\begin{array}{l}144,0 \\
138,6 \\
118,5 \\
137,5 \\
169,9 \\
311,1 \\
240,8 \\
171,1 \\
152,3 \\
156,3\end{array}$ & $\begin{array}{l}287,5 \\
292,8 \\
294,3 \\
323,7 \\
309,7 \\
254,9 \\
280,8 \\
360,2 \\
340,2 \\
329,7\end{array}$ & $\begin{array}{l}812,6 \\
796,0 \\
772,1 \\
839,4 \\
825,0 \\
892,7 \\
888,1 \\
909,1 \\
872,3 \\
862,9\end{array}$ & $\begin{array}{l}403,0 \\
384,6 \\
380,0 \\
402,0 \\
369,6 \\
348,9 \\
389,9 \\
399,2 \\
400,4 \\
396,4\end{array}$ & $\begin{array}{l}144,0 \\
138,6 \\
118,5 \\
137,5 \\
169,9 \\
311,1 \\
240,8 \\
171,1 \\
152,3 \\
156,3\end{array}$ & $\begin{array}{l}289,2 \\
299,0 \\
196,0 \\
352,2 \\
311,2 \\
255,8 \\
282,0 \\
361,3 \\
341,4 \\
331,2\end{array}$ & $\begin{array}{l}836,2 \\
822,2 \\
794,5 \\
864,7 \\
850,7 \\
915,8 \\
912,7 \\
931,6 \\
894,1 \\
883,9\end{array}$ \\
\hline $\begin{array}{l}1910 \\
1911 \\
1912 \\
1913\end{array}$ & $\begin{array}{l}398,0 \\
448,7 \\
527,5 \\
590,8\end{array}$ & $\begin{array}{l}194,4 \\
218,4 \\
202,4 \\
270,0\end{array}$ & $\begin{array}{l}393,1 \\
428,7 \\
494,2 \\
569,8\end{array}$ & $\begin{array}{r}985,5 \\
1.095,8 \\
1.224,1 \\
1.430,6\end{array}$ & $\begin{array}{l}418,8 \\
470,9 \\
552,2 \\
617,9\end{array}$ & $\begin{array}{l}194,4 \\
218,4 \\
202,4 \\
270,0\end{array}$ & $\begin{array}{l}393,8 \\
429,8 \\
495,9 \\
570,9\end{array}$ & $\begin{array}{l}1.007,0 \\
1.119,1 \\
1.250,5 \\
1.458,8\end{array}$ \\
\hline
\end{tabular}

Furntes: Véase el texto. 


\section{CUADRO AP-6}

Importaciones netas c.i.f. (10 pesetas corrientes), 1849-1913

\begin{tabular}{|c|c|c|c|c|c|c|c|c|}
\hline \multirow[b]{2}{*}{ Años } & \multicolumn{4}{|c|}{ IMPORTACIONES DIRFCTAS } & \multicolumn{4}{|c|}{ IMPORTACIONES TOTALES } \\
\hline & $\begin{array}{c}\text { Manu- } \\
\text { facturas }\end{array}$ & $\begin{array}{c}\text { Ali. } \\
\text { mentos }\end{array}$ & $\begin{array}{l}\text { Materias } \\
\text { primas }\end{array}$ & Total & $\begin{array}{l}\text { Manu- } \\
\text { facturas }\end{array}$ & $\begin{array}{c}\text { Ali. } \\
\text { mentos }\end{array}$ & $\begin{array}{c}\text { Materias } \\
\text { primas }\end{array}$ & Total \\
\hline $\begin{array}{l}1849 \\
1850 \\
1851 \\
1852 \\
1853 \\
1854 \\
1855 \\
1856 \\
1857 \\
1858 \\
1859\end{array}$ & $\begin{array}{r}75,5 \\
81,6 \\
78,5 \\
90,8 \\
101,7 \\
99,8 \\
117,1 \\
154,1 \\
167,4 \\
176,8 \\
156,8\end{array}$ & $\begin{array}{r}40,5 \\
45,8 \\
44,2 \\
50,4 \\
44,8 \\
57,4 \\
70,6 \\
88,6 \\
143,6 \\
109,6 \\
76,1\end{array}$ & $\begin{array}{l}25,4 \\
35,4 \\
33,9 \\
30,4 \\
29,2 \\
37,7 \\
49,2 \\
66,9 \\
46,3 \\
64,8 \\
65,8\end{array}$ & $\begin{array}{l}141,4 \\
162,8 \\
156,6 \\
171,6 \\
175,7 \\
194,9 \\
236,9 \\
309,6 \\
357,3 \\
351,2 \\
298,7\end{array}$ & $\begin{array}{r}86,0 \\
91,8 \\
90,3 \\
103,4 \\
117,4 \\
118,0 \\
136,3 \\
174,8 \\
184,2 \\
204,3 \\
174,2\end{array}$ & $\begin{array}{r}40,5 \\
45,8 \\
44,2 \\
50,4 \\
44,8 \\
57,4 \\
70,6 \\
88,6 \\
143,6 \\
109,6 \\
76,1\end{array}$ & $\begin{array}{l}28,2 \\
36,1 \\
34,6 \\
31,2 \\
29,9 \\
39,5 \\
50,4 \\
68,2 \\
48,4 \\
66,2 \\
66.7\end{array}$ & $\begin{array}{l}154,7 \\
173,7 \\
169,1 \\
185,0 \\
192,1 \\
214,9 \\
257,3 \\
331,6 \\
376,2 \\
380,1 \\
317,0\end{array}$ \\
\hline $\begin{array}{l}1860 \\
1861 \\
1862 \\
1863 \\
1864 \\
1865 \\
1866 \\
1867 \\
1868 \\
1869\end{array}$ & $\begin{array}{l}185,2 \\
238,5 \\
247,5 \\
300,4 \\
283,7 \\
244,3 \\
208,1 \\
180,5 \\
148,7 \\
170,6\end{array}$ & $\begin{array}{r}83,3 \\
89,4 \\
106,2 \\
129,4 \\
154,5 \\
120,8 \\
98,6 \\
81,9 \\
223,2 \\
108,4\end{array}$ & $\begin{array}{l}77,0 \\
97,7 \\
82,7 \\
99,3 \\
99,8 \\
78,2 \\
89,8 \\
73,5 \\
50,9 \\
78,7\end{array}$ & $\begin{array}{l}345,5 \\
425,6 \\
436,4 \\
529,1 \\
538,0 \\
443,3 \\
396,5 \\
335,9 \\
422,8 \\
357,7\end{array}$ & $\begin{array}{l}210,9 \\
265,2 \\
271,4 \\
331,5 \\
312,3 \\
271,4 \\
234,7 \\
199,5 \\
167,7 \\
190,8\end{array}$ & $\begin{array}{r}83,3 \\
89,4 \\
106,2 \\
129,4 \\
154,5 \\
120,8 \\
98,6 \\
81,9 \\
223,2 \\
108,4\end{array}$ & $\begin{array}{r}80,4 \\
99,8 \\
86,2 \\
103,1 \\
101,7 \\
80,1 \\
92,6 \\
78,0 \\
56,9 \\
86,0\end{array}$ & $\begin{array}{l}374,6 \\
454,4 \\
463,8 \\
564,0 \\
568,5 \\
472,3 \\
425,9 \\
359,4 \\
447,8 \\
385,2\end{array}$ \\
\hline $\begin{array}{l}1870 \\
1871 \\
1872 \\
1873 \\
1874 \\
1875 \\
1876 \\
1877 \\
1878 \\
1879\end{array}$ & $\begin{array}{l}173,1 \\
207,0 \\
224,9 \\
226,7 \\
272,4 \\
259,0 \\
298,7 \\
258,8 \\
257,9 \\
272,2\end{array}$ & $\begin{array}{r}84,8 \\
81,5 \\
127,0 \\
75,0 \\
74,5 \\
59,4 \\
73,1 \\
78,7 \\
82,0 \\
113,5\end{array}$ & $\begin{array}{r}105,3 \\
131,9 \\
207,9 \\
73,9 \\
143,7 \\
126,4 \\
124,8 \\
126,3 \\
113,1 \\
112,1\end{array}$ & $\begin{array}{l}362,2 \\
420,4 \\
559,8 \\
375,6 \\
490,6 \\
444,8 \\
496,6 \\
463,8 \\
452,9 \\
497,8\end{array}$ & $\begin{array}{l}193,3 \\
231,1 \\
253,5 \\
258,1 \\
302,0 \\
286,4 \\
326,6 \\
282,6 \\
278,5 \\
291,6\end{array}$ & $\begin{array}{r}84,8 \\
81,5 \\
127,0 \\
75,0 \\
74,5 \\
59,4 \\
73,1 \\
78,7 \\
82,0 \\
113,5\end{array}$ & $\begin{array}{r}116,4 \\
143,1 \\
221,4 \\
81,3 \\
151,4 \\
129,9 \\
129,6 \\
134,6 \\
122,0 \\
116,7\end{array}$ & $\begin{array}{l}394,5 \\
455,7 \\
601,9 \\
414,4 \\
527,9 \\
475,7 \\
529,3 \\
495,9 \\
482,5 \\
521,8\end{array}$ \\
\hline $\begin{array}{l}1880 \\
1881 \\
1882 \\
1883 \\
1884 \\
1885 \\
1886 \\
1887 \\
1888 \\
1889\end{array}$ & $\begin{array}{l}282,4 \\
291,9 \\
349,3 \\
405,3 \\
373,6 \\
350,2 \\
354,6 \\
317,3 \\
346,2 \\
424,3\end{array}$ & $\begin{array}{l}136,8 \\
112,0 \\
176,1 \\
209,1 \\
138,2 \\
166,3 \\
191,5 \\
193,0 \\
150,6 \\
144,6\end{array}$ & $\begin{array}{l}176,1 \\
139,4 \\
155,9 \\
200,8 \\
164,4 \\
156,0 \\
158,1 \\
151,3 \\
155,4 \\
232,9\end{array}$ & $\begin{array}{l}595,3 \\
543,3 \\
681,3 \\
815,2 \\
676,2 \\
672,5 \\
704,2 \\
661,6 \\
652,2 \\
801,9\end{array}$ & $\begin{array}{l}303,7 \\
312,7 \\
370,6 \\
426,1 \\
394,1 \\
368,8 \\
373,0 \\
341,2 \\
367,5 \\
448,4\end{array}$ & $\begin{array}{l}136,8 \\
112,0 \\
176,1 \\
209,1 \\
138,2 \\
166,3 \\
191,5 \\
193,0 \\
150,6 \\
144,6\end{array}$ & $\begin{array}{l}184,0 \\
149,2 \\
160,6 \\
202,9 \\
168,3 \\
160,4 \\
161,3 \\
155,4 \\
157,5 \\
234,7\end{array}$ & $\begin{array}{l}624,5 \\
573,9 \\
707,3 \\
838,1 \\
700,6 \\
695,5 \\
725,8 \\
689,6 \\
675,6 \\
827,7\end{array}$ \\
\hline
\end{tabular}


CUADRO AP-6 (Continuación)

Importaciones netas c.i.f. (106 pesetas corrientes), 1849-1913

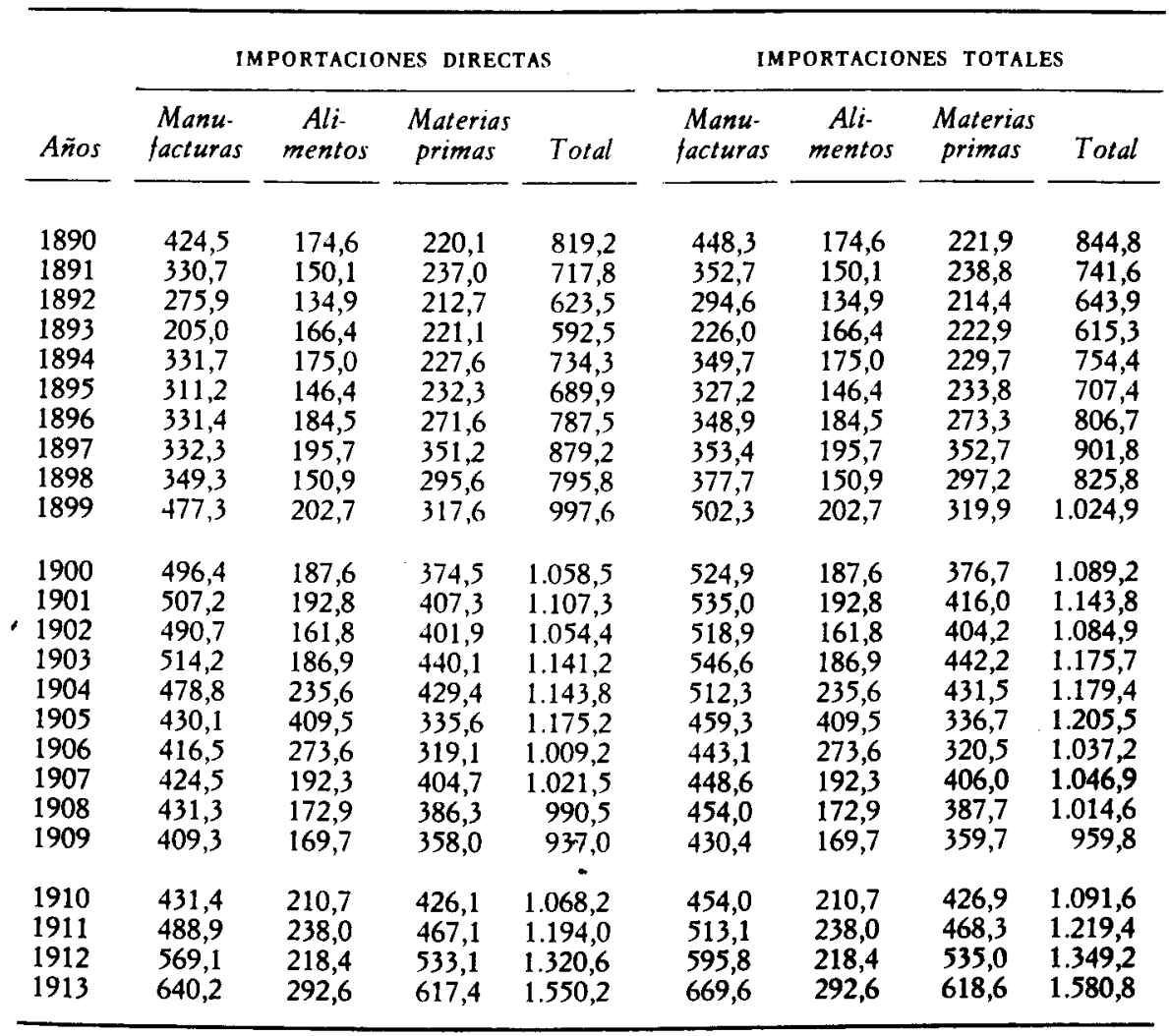

Fuentes: Véase el texto. 


\section{CUADRO AP.7}

Coeficience de depreciación de la peseta, 1821-1913

[peseta-oro/peseta corriente]

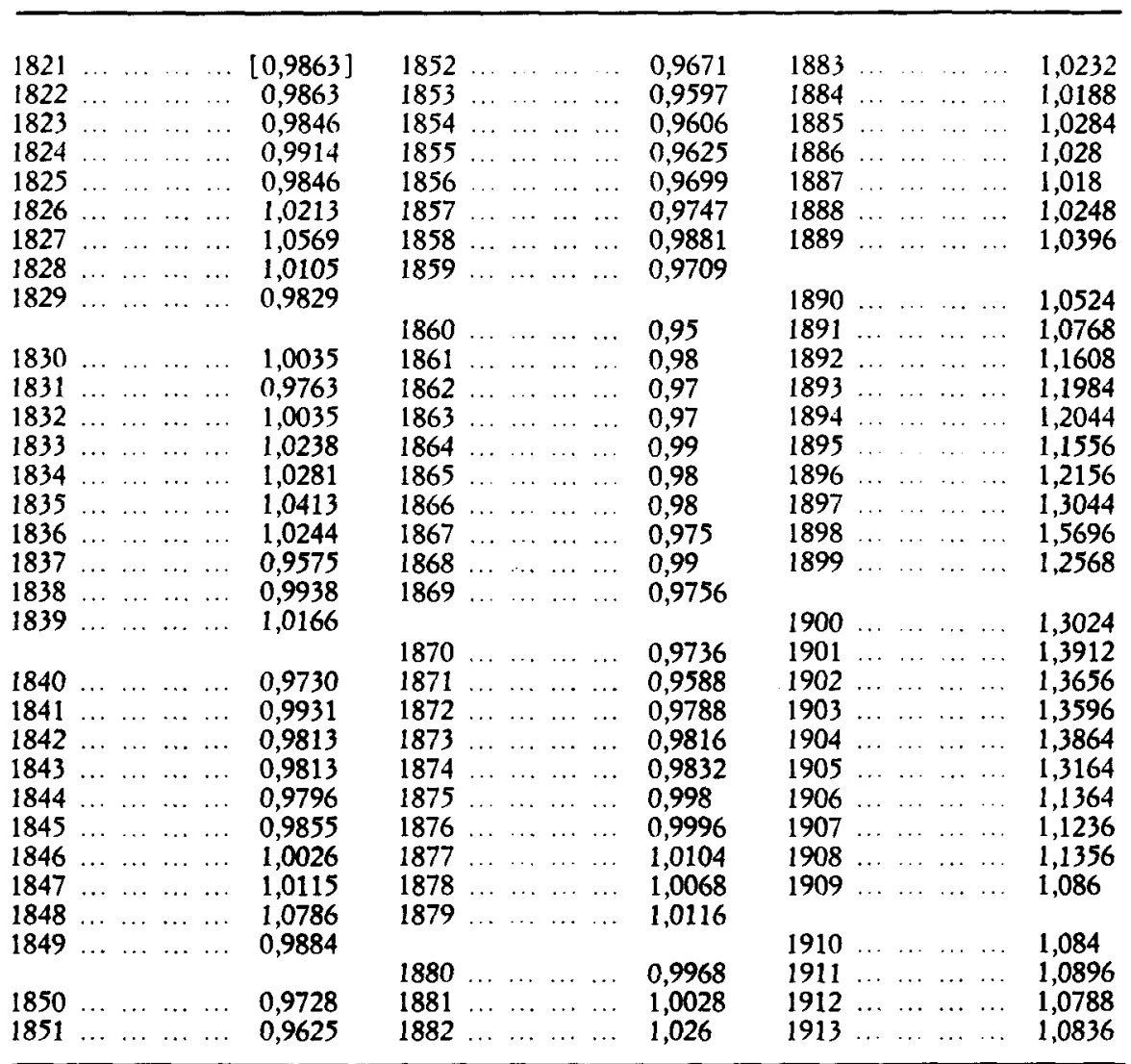

Fuentes: 1821-1844: London Price Current(s); 1845-1860: The Economist; 1861-1874: British Parliamentary Papers (1892), LXXXIV, 215; 1875-1913: G. ToRTELLA, P. Martín aceña, J. Sanz y S. Zapata (1978), «Las balanzas del comercio exterior español: un experimento histórico-estadístico, 1875-1913», en J. L. GARcía Delgado y J. Segura (eds.) (1978), Ciencia Social y Análisis Económico. Estudios en bomenaje al profesor Valentin Andrés Alvarez, Madrid, p. 505. 


\section{BIBLIOGRAFIA}

Alvarez Alonso, L. (1985): La politica comercial española, 1849-1891, tesis de licenciatura, Universidad de Valencia.

ANDRÉs Alvarez, V. (1943): "Historia y crítica de los valores de nuestras balanzas de comercio», Moneda y Crédito, 4; reproducido en Velarde (1969): 536-549.

- (1945): «Las balanzas. Estadísticas de nuestro comercio exterior», Revista de Economía Política, I; reproducido en Velarde (1969): 550-565.

Anes, G. (1974): El Antiguo Régimen. Los Borbones, Madrid.

ANEs, G.; Rojo, L. A., y TEDdE, P. (eds.) (1983): Historia económica y pensamiento social, Madrid.

Bennassar, B. (ed.) (1985): Orígenes del atraso económico español, Barcelona; edición original francesa (1983): Aux origines du retard économique de l'Espagne (XV'-XIXe siecles), París.

BRODER, A. (1976): «Les investissements étrangers en Espagne au xix siècle: méthodologie et quantification», Revue d'Histoire Economique et Sociale, 54, 1: 29-63.

Broder, A.; Chastagneret, G., y Témime, E. (1985): “Capital y crecimiento en la España del siglo XIX», en Bennassar (ed.) (1985): 83-143.

Chamorro, S.; Comendador, R.; Dolado, J. J.; Repullo, R., y Rodríguez, J. (1975): «Las balanzas de pagos de España en el período de la Autarquía», Información Comercial Española, 502: 161-189.

Fontana, J. (ed.) (1982): La economía española al final del Antiguo Régimen. III. Comercio y colonias, Madrid.

GwinNer, A. (1973): «La política comercial de España en los últimos decenios», en F. Estapé (ed.): Textos olvidados, Madrid: 261.333.

League of Nations (1924): Memorandum on Balance of Payments and Foreign Trade Balances, 1910-1923, 2 vols., Ginebra.

LÉVY-LEBOYER, M. (1970): «L'héritage de Simiand: prix, profit et termes d'échange au $\mathrm{xIX}^{e}$ siècle», Revue Historique, 94, 243: 77-120.

- (1977): "La balance des paiements et l'exportation des capitaux français», en M. LévyLeboyer (ed.): La position internationale de la France. Aspects économiques et financiers $X I X^{c}-X X^{c}$, París: $75-142$.

LEwIS, W. A. (1978): Growth and Fluctuations, 1870-1913, Londres.

MALuQuer de Motes, J. (1974): «El mercado colonial antillano en el siglo xIX», en Nadal y Tortella (eds.) (1974): 322-357.

Martín Aceña, P., y Prados de la Escosura, L. (eds.) (1985): La Nueva Historia Económica en España, Madrid.

Martf́nez MÉnDEZ, P. (1983): «Nuevos datos sobre la evolución de la peseta entre 1900 y 1936\%, en Anes, Rojo y Tedde (eds.) (1983): 561-610.

Matilla Tascón, A. (1964): Balanza del comercio exterior de España en el año 1795, Madrid.

Nadal, J., y Tortella, G. (eds.) (1974): Agricultura, comercio colonial y crecimiento económico en la España contemporánea, Barcelona.

Nort H, D. C. (1958): «Ocean Freight Rates and Economic Development, 1750-1913», Journal of Economic History, XVIII: 537-555.

- (1960): "The United States Balance of Payments, 1790-1860», en Parker (ed.) (1960): $573-627$.

Nort H, D. C., y Heston, A. (1960): "The Estimation of Shipping Earnings in the Historical Studies of the Balance of Payments», Canadian Journal of Economics and Political Science, XXVI: 265-276.

PARKER, W. N. (ed.) (1960): Trends in the American Economy in the Nineteenth Century, Princeton, NBER Studies in Income and Wealth, vol. 24.

Post Humus, N. W. (1946): The History of Prices in Holland, 2 vols., Leiden.

Prados de la Escosura, L. (1981): «Las estadísticas españolas de comercio exterior, 1850-1913: el problema de las "valoraciones"», Moneda y Crédito, 156: 43-60. 
Prados de la Escosura, L. $(1982 a)$ : "Comercio exterior y cambio económico en España (1792-1849)", en Fontana (ed.) (1982): 171-249.

- (1982 b): Comercio exterior y crecimiento conómico en España. 1826-1913: tendencias a largo plazn, Madrid.

- (1984 a): "La evolución del comercio exterior, 1792-1929", Papeles de Economía Española, 20: 135-150.

- (1984 b): «El comercio hispano-británico en los siglos xvin y xIx. I. Reconstrucción», Revista de Historia Económica, II, 2: 113-162

- (1985): «Las relaciones reales de intercambio entre España y Gran Bretaña en los siglos xvilı y xix», en Martín Aceña y Prados de la Escosura (eds.) (1985): 119-165.

- (1986 a): El atraso económico de España (1780-1914), Madrid.

- (1986 b): «El comercio hispano-británico en los siglos xvill y xIx: tendencia y estructura», Revista de Historia Económica, IV, 3.

SÁnC h EZ-Albornoz, N. (1979): Los precios del vino en España, 1861-1890 (documento de trabajo), Banco de España, Madrid.

- (ed.) (1981): Los precios agricolas durante la segunda mitad del siglo XIX, vol. II: Vino y aceite, Madrid.

SARDÁ, J. (1948): La politica monetaria y las fluctuaciones de la economía española en el siglo $X I X$, Madrid.

Simon, M. (1960): "The United States Balance of Payments, 1861-1900», en Parker (ed.) (1960): 629-711.

TÉmime, E.; Broder, A., y Chastagneret, G. (1982): Historia de la España contemporánea. Desde 1808 hasta nuestros dias, Barcelona; edición original francesa (1979): Histoire de l'Espagne contemporaine. De 1808 à nos jours, París.

TENA, A. (1985): «Una reconstrucción del comercio exterior español, 1914-1935: la rectificación de las estadísticas oficiales». Revista de Historia Económica, III, 1: 77-119.

ToRTELLA, G. (1974): «Las magnitudes monetarias y sus determinantes», en P. Schwartz y G. Tortella (eds.): La Banca española en la Restauración, 2 vols., Madrid.

- (1981): «La economía española, 1830-1900», en M. Tuñón de Lara (ed.): Revolución burguesa, oligarquia y constitucionalismo (1834-1923), Barcelona: 9-167.

Tortella, G.; Martín Aceña, P.; Sanz, J., y Zapata, S. (1978): «Las balanzas del comercio exterior español: un experimento histórico-estadístico, 1875-1913m, en J. L. García Delgado y J. Segura (eds.): Ciencia Social y Análisis Económico. Estudios en bomenaje al protesor Valentín Andrés Alvarez. Madrid: 487-513.

VAnDellós, I. A. (1931): «Las balanzas comerciales y el cambio de la peseta», Revista Nacional de Economia, XXXII, 3-12.

Velarde, J. (et.) (1969): Lecturas de cconomia española, Madrid.

Vicens Vives, J. (1959): Manual de Historia Económica de España, Barcelona. 